Magazine of Concrete Research Volume 63 Issue 2

Influence of beam cross-section, loading arrangement and aggregate type on shear strength

Sagaseta and Vollum
Magazine of Concrete Research, 2011, 63(2), 139-155

\title{
Influence of beam cross- section, loading arrangement and aggregate type on shear strength
}

\author{
J. Sagaseta \\ École Polytechnique Fédérale de Lausanne (EPFL), \\ Lausanne, Switzerland
}

\section{R. L. Vollum}

Department of Civil and Environmental Engineering, Imperial College London, London, UK

This paper describes 14 tests on simply supported and continuous reinforced concrete beams which were designed to investigate the influences of aggregate type, loading arrangement and shear reinforcement ratio on shear strength. The beams were rectangular in cross-section with $a / d \sim 3.5$ (where $a$ is the shear span and $d$ the effective depth). Marine dredged gravel was used in ten beams (two without shear reinforcement) and limestone in the remaining four (two without shear reinforcement). The cracks typically passed around the gravel aggregate but through the limestone aggregate. Aggregate fracture was found only to reduce the shear strength of the beams without shear reinforcement. The factors of safety for shear failure implicit in Eurocode 2, BS 8110 and CSA A.23.3-04 are examined with data from this project and elsewhere. Eurocode 2 is shown to provide the lowest factor of safety for most beams. This is particularly significant for rectangular sections where Eurocode 2 can give lower factor of safety for shear than flexural failure which is undesirable. An amendment is proposed to address this.

\section{Notation}

a maximum aggregate size

$b \quad$ beam width

$b_{\mathrm{f}} \quad$ width of compression flange

C cohesion

d effective depth

EC2 Eurocode 2

FOS factor of safety (FOS for shear $=V_{\text {design }}$ divided by overall load factor)

$f_{\mathrm{c}}^{\prime} \quad$ concrete cylinder strength

$f_{\text {cu }} \quad$ concrete cube strength

$f_{\mathrm{y}} \quad$ yield strength of reinforcement (subscript

$k=$ characteristic value)

$h_{\mathrm{f}} \quad$ depth of compression flange

$P_{\text {cr }} \quad$ load at which first cracks originated

$P_{\text {ult }} \quad$ ultimate failure load

SI $\quad$ stirrup index SI $=\rho_{\mathrm{w}} f_{\mathrm{y}} /\left(v f_{\mathrm{c}}^{\prime}\right)$

$s \quad$ stirrup spacing

$V \quad$ shear force

$V_{\text {c }} \quad$ concrete component of shear resistance

$V_{\mathrm{cz}} \quad$ shear carried by the compression zone

$V_{\text {design }}$ design ultimate shear resistance divided by overall load factor

$V_{\mathrm{Rdc}} \quad$ EC2 design shear resistance for beams without shear reinforcement

$V_{\mathrm{s}} \quad$ stirrup contribution to shear resistance

VSI EC2 variable strut inclination design method

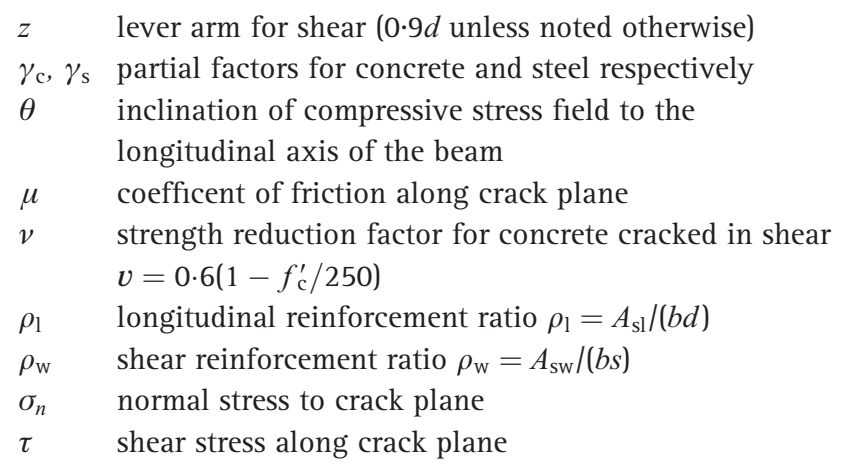

\section{Introduction}

Shear is resisted in beams through the combined contributions of the compression zone at the head of the shear crack, aggregate interlock, dowel action and stirrups if present. The contribution of each mechanism has been keenly debated since pioneering work by Taylor (1970) and others showed that aggregate interlock contributes up to $50 \%$ of the shear strength of beams without stirrups. This paper considers the influences of aggregate fracture and beam cross-section geometry on the factors of safety (FOS) for shear implicit in EC2 (Eurocode 2) (BSI, 2004), BS 8110-1: 1997 (BSI, 2007) and CSA A.23.3-04 (CSA, 2004). These design methods are refinements of the classical $45^{\circ}$ truss analogy in which the shear strength is taken as $V=V_{\mathrm{c}}+V_{\mathrm{s}}$ where $V_{\mathrm{c}}$ and $V_{\mathrm{s}}$ represent the contributions of the concrete and shear reinforcement respectively. BS 8110-1:1997 (BSI, 2007) takes $V_{\mathrm{c}}$ as the 
shear strength of beams without stirrups and calculates $V_{\mathrm{s}}$ with a $45^{\circ}$ truss. EC2 (BSI, 2004) uses a variable strut inclination method in which the shear force is assumed to be entirely resisted by the shear reinforcement (i.e. $V_{\mathrm{c}}=0$ ). The Canadian code CSA A.23.3-04 (CSA, 2004) is derived from the modified compression field theory (MCFT) of Vecchio and Collins (1986). The latter two methods relate $V_{\mathrm{c}}$ to the strain in the flexural reinforcement as described by Collins et al. (2008).

\section{Influence of aggregate fracture on shear strength}

In high-strength (HSC) and lightweight aggregate concrete (LWAC), the bond between the aggregate particles and the cement paste can be strong enough for the aggregate to fracture at cracks, as shown in Figure 1. Aggregate fracture results in smoother crack surfaces and can reduce shear transfer through aggregate interlock. A similar situation arises in self-compacting concretes (SCC) where cracks are relatively smooth owing to the reduced content of coarse aggregates (Lachemi et al., 2005).

The literature provides conflicting views on the effect of aggregate fracture on shear strength. For example, Walraven and Stroband (1994) found that aggregate fracture reduced the shear strength of their HSC push-off specimens. Conversely, Walraven and Al-Zubi (1995) and Walraven and Stroband (1999) tested LWAC and HSC beams with stirrups and found no reduction in shear strength owing to aggregate fracture. They explained this behaviour in terms of irregularities in the crack surface at a macro-level. On the other hand, Hamadi and Regan (1980) found that the shear strength of their beams with stirrups made from expanded clay LWAC was reduced by aggregate fracture. More recently, Regan et al. (2005) tested a series of beams without stirrups and found that the shear strength was reduced if the coarse aggregate fractured at cracks. They speculated that the shear strength of beams with stirrups would be reduced by aggregate fracture but were unable to quantify the reduction owing to insufficient experimental data.

\section{Code provisions for influence of crack roughness on shear strength}

Regan's work (Regan et al., 2005) led to the UK national annex to EC2 (BSI, 2005) limiting the maximum allowable concrete cylinder strength to be used in the shear provisions of the code to $50 \mathrm{MPa}$ unless justified otherwise. More rational alternatives to limiting the concrete strength are the MCFT of Vecchio and Collins (1986) and the critical shear crack theory of Muttoni and Fernández Ruiz (2008) which are incorporated into the Canadian CSA A.23.304 (CSA, 2004)) and Swiss SIA262 (SIA, 2003) codes respectively. Both these methods express the crack roughness in terms of the maximum aggregate size (a) and account for aggregate fracture by reducing the aggregate size linearly to zero for concrete cylinder strengths between $60 \mathrm{MPa}$ and $70 \mathrm{MPa}$ (Angelakos et al., 2001). Even so, the MCFT neglects the influence of previous cracks since it is a fully rotational crack approach in which shear stresses are checked along fictitious cracks which are assumed to be oriented parallel to the principal compressive stress field.

\section{Contribution of compression flange to shear strength}

EC2, BS 8110 and CSA A.23.3-04 assume that the shear force is entirely carried by the web in ' $\mathrm{I}$ ' and ' $\mathrm{T}$ ' sections and attribute the contribution of the compression flange to the web. Therefore, it is striking that the variable strut inclination (VSI) method in EC2 was validated with data from tests on highly stressed simply supported beams with 'I' and ' $T$ ' sections (Walraven, 2004) in which the compression flange contributed significantly, but

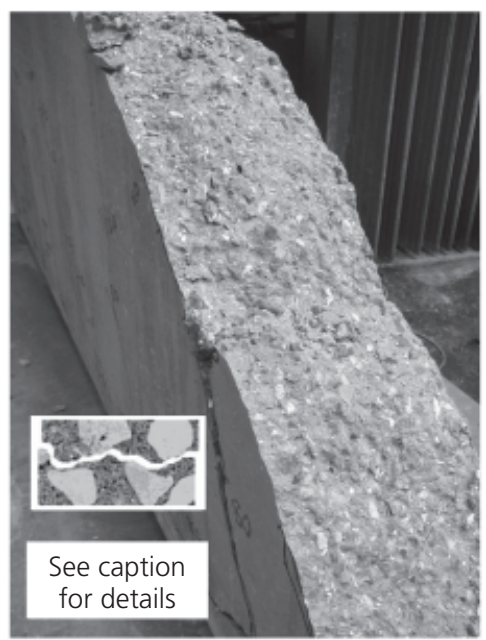

(a)

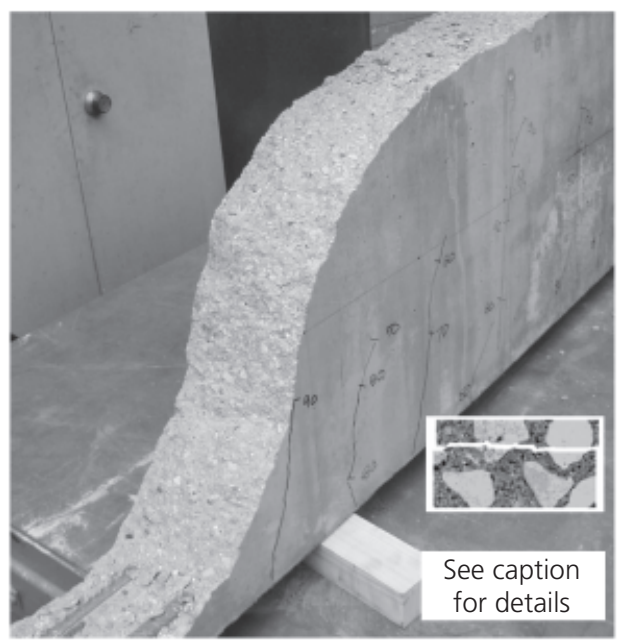

(b)

Figure 1. Failure surface at critical shear crack in beams without stirrups: (a) rough crack surface in beam BGO $\left(f_{c}^{\prime}=80.2 \mathrm{MPa}\right)$ with gravel aggregate; and (b) smooth crack surface due to aggregate fracture in beam BLO ( $\left.f_{c}^{\prime}=68.4 \mathrm{MPa}\right)$ with limestone aggregate 
indeterminately, to shear strength. There is a scarcity of tests on continuous beams which is unfortunate since continuous beam tests have several advantages over simply supported beam tests as noted by Leonhardt and Walther (1961). First, the compression zone contributes less to shear strength in continuous than simply supported beams. It follows that tests on simply supported ' $\mathrm{T}$ ' and 'I' sections are not directly applicable to continuous beams owing to the reversal of bending moment within the critical section for shear. Second, the stress state in continuous beams is closer to pure shear than in simply supported beams. Third, shear failure is obtainable at much greater shear reinforcement ratios in continuous than simply supported beams with rectangular sections. The greater $M / V$ ratio in simply supported beams necessitates the use of ' $\mathrm{T}$ ' or ' $\mathrm{I}$ ' cross-sections with relatively thin webs at high shear reinforcement ratios. The present paper examines the consequences of not explicitly considering the contribution of the compression flange to shear strength by comparing measured and predicted shear strengths for rectangular, ' $\mathrm{T}$ '- and ' $\mathrm{I}$ '-shaped cross-sections with similar shear reinforcement ratios.

\section{Experimental investigation}

The authors tested 14 beams (four without shear reinforcement) to investigate the influences of aggregate fracture, beam crosssection and loading arrangement on shear strength. Marine dredged gravel was used in ten beams and limestone in the remaining four. The maximum size of the aggregate was $10 \mathrm{~mm}$ in all the beams. The cracks typically passed around the gravel aggregate but through the limestone aggregate. The primary aim of the tests was to determine whether (a) the shear strength of beams with shear reinforcement is significantly reduced by aggre- gate fracture and (b) to assess the safety of code guidelines for shear in highly stressed beams without compression flanges.

\section{Beams without shear reinforcement}

Four beams were tested without stirrups to determine whether the reduction in shear strength owing to aggregate fracture was comparable to that found by Regan et al. (2005). Figure 2 shows the geometry of the tested beams and the loading configuration. Two beams were cast from concrete with marine (siliceous) gravel aggregate and two with limestone (calcareous) crushed aggregate. The main characteristics of the beams and their failure loads are summarised in Table 1 in which ' $G$ ' denotes gravel and ' $\mathrm{L}$ ' denotes limestone aggregate. The concrete cylinder strengths were $80.2 \mathrm{MPa}$ and $68.4 \mathrm{MPa}$ for the BG0 and BL0 beams respectively. The ratio of the shear span to the effective depth $(a / d)$ was 3.44 . The flexural reinforcement was the same in all the beams and consisted of $2 \mathrm{~T} 20$ bars $\left(\rho_{1}=1 \%\right)$ with a yield strength of $580 \mathrm{MPa}$.

All the beams failed in shear as shown in Figure 3. The critical shear crack initiated at a previous flexural-shear crack and propagated suddenly to the load and support plates. Figure 3(c) shows that the angle between the longitudinal reinforcement and the critical diagonal crack was steeper in the BL than the BG specimens. The top halves of the beams were removed after testing to inspect the crack surfaces. Figure 1 shows that the aggregate fractured completely in the BL beams $\left(f_{\mathrm{c}}^{\prime}=68.4 \mathrm{MPa}\right)$ but not in the gravel beams $\left(f_{\mathrm{c}}^{\prime}=80.2 \mathrm{MPa}\right)$ where the crack went through around $30 \%$ of the aggregate. Figure 1 shows that the crack

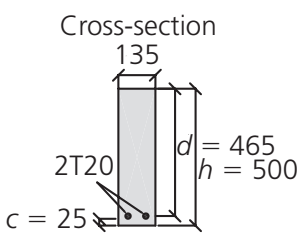

(a)

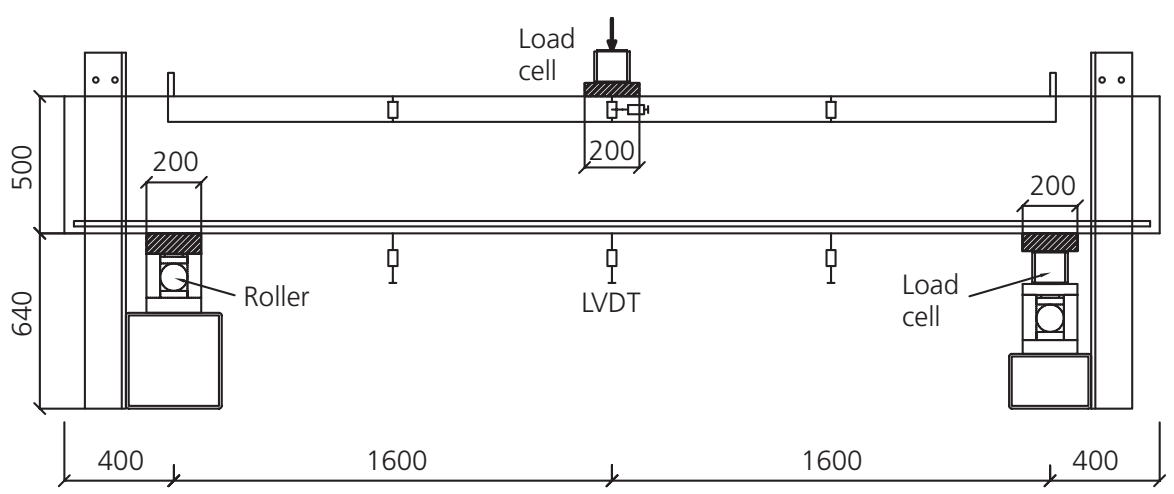

(b)

Figure 2. Test arrangement for beams BO (dimensions in $\mathrm{mm}$ ):

(a) cross-section; and (b) geometry and instrumentation 


\begin{tabular}{lccccccc}
\hline Beam & $f_{\mathrm{c}}^{\prime}:$ MPa & $f_{\mathrm{y}}$ (long.): MPa & $\rho_{l}: \%$ & a/d & $\delta_{\text {centre: } \mathrm{mm}}$ & $P_{\text {cr }}: \mathrm{kN}$ & $P_{\text {ult: }}: \mathrm{kN}$ \\
\hline BG01 & $80 \cdot 20$ & 580 & 1 & $3 \cdot 46$ & $4 \cdot 14$ & $56 \cdot 2$ & $122 \cdot 63$ \\
BG02 & $80 \cdot 20$ & 580 & 1 & 3.46 & $4 \cdot 70$ & $50 \cdot 0$ & $126 \cdot 22$ \\
BL01 & $68 \cdot 44$ & 580 & 1 & $3 \cdot 46$ & $3 \cdot 58$ & $50 \cdot 0$ & $93 \cdot 72$ \\
BL02 & $68 \cdot 44$ & 580 & 1 & $3 \cdot 46$ & $4 \cdot 27$ & $50 \cdot 0$ & $108 \cdot 14$ \\
\hline
\end{tabular}

Notes: $\delta_{\text {centre }}^{*}$ central deflection at failure load; $P_{\text {cr }}$ load at which cracks were first observed; all beams failed in diagonal tension

Table 1. Experimental data for beams without shear

reinforcement

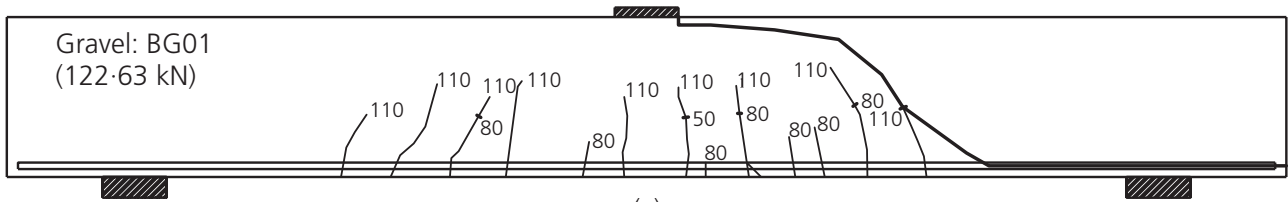

(a)

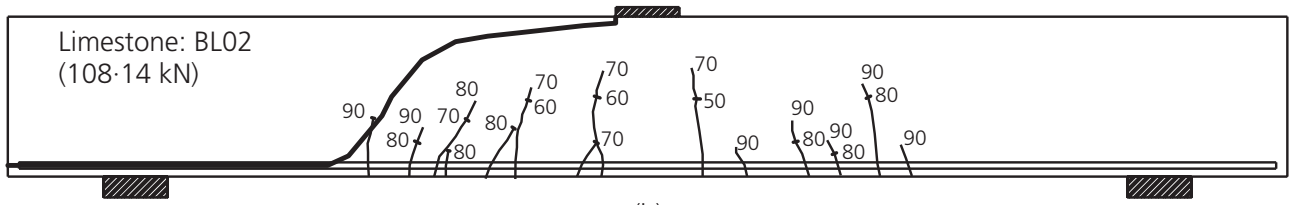

(b)

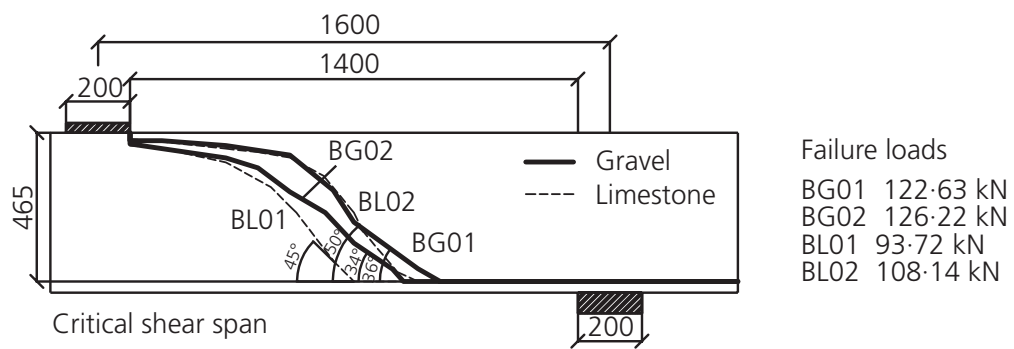

(c)

Figure 3. Crack patterns in beams B0 (the numbers along the cracks denote the load at which the cracks were first observed in kN; critical cracks are highlighted in bold): (a) BG01; (b) BL02; and $(c)$ relative position of main diagonal shear cracks

roughness depends on the aggregate type and not just the concrete strength as commonly assumed in codes of practice.

\section{Comparison between measured and predicted shear} strengths of beams BGO and BLO

The shear strengths of the BG0 and BL0 beams are not directly comparable due to unintended differences in concrete strength. Therefore, the effect of aggregate fracture was determined indirectly by comparing the strengths of the beams with the predictions of various design methods including Eurocode 2 (BSI, 2004) which takes the shear strength as

$$
\text { 1. } V_{\mathrm{Rd}, \mathrm{c}}(\mathrm{EC} 2)=\frac{0 \cdot 18}{\gamma_{\mathrm{c}}}\left(100 \rho_{1} f_{\mathrm{c}}^{\prime}\right)^{1 / 3}(1+\sqrt{200 / d}) b d
$$

where $\rho_{1}$ is the longitudinal reinforcement ratio, $f_{\mathrm{c}}^{\prime}$ is the cylinder compressive strength, $d$ is the effective depth, $\gamma_{c}$ is the partial 
factor for concrete which is taken as 1.5 for design, and $b$ is the beam width

The measured and calculated shear strengths are compared in Table 2 which gives strengths calculated with the partial factor $\gamma_{c}$ equal to both 1.0 and 1.5 with the latter values shown in parentheses. $V_{\mathrm{Rdc}}$ was calculated with both the actual concrete strength and the maximum strength of $f_{\mathrm{ck}}=50 \mathrm{MPa}$ allowed by the UK national annex to EC2. Table 2 shows that $V_{\text {test }} / V_{\text {Rdc }}$ (with $\gamma_{\mathrm{c}}=1 \cdot 0$ ) was less than 1 for all the beams and furthermore, $V_{\text {test }} / V_{\text {Rdc }}$ was $16 \%$ lower for the limestone than for the gravel beams. Limiting the concrete cylinder strength to $50 \mathrm{MPa}$ noticeably improved the predictions for the gravel beams, which had a concrete strength of $80.2 \mathrm{MPa}$. This was less so for the limestone beams where the concrete strength of $68.4 \mathrm{MPa}$ is closer to the cut-off of $50 \mathrm{MPa}$ in the UK national annex to EC2. Table 2 also shows that limiting the concrete cylinder strength to $50 \mathrm{MPa}$ gives safe results when $\gamma_{\mathrm{c}}=1 \cdot 5$. The main drawback with limiting the concrete strength is that the influence of aggregate type is neglected.

Regan et al. (2005) used the interpolated surfaces $\left(V_{\text {test }} / V_{\text {calc }}-f_{\mathrm{c}}-\right.$ d) shown in Figure 4 to illustrate the worsening predictions of Equation 1 for their beams, with limestone and gravel aggregates, with increasing member depth $(d)$ and concrete strength $\left(f_{\mathrm{c}}^{\prime}\right)$. Figure 4 shows $V_{\text {test }} / V_{\text {calc }}$ is lower for the authors' beams with limestone than gravel aggregate and the authors' data lie close to the interpolated surfaces of Regan et al. (2005).

The shear strengths of the B0 beams were also calculated with the MCFT using the programme Response 2000 (Bentz, 2000). Shear strengths were calculated with maximum aggregate sizes of $a=10 \mathrm{~mm}$ and $a=0$. Table 2 shows that the MCFT predicted the shear strengths of the tested beams more accu- rately than Equation 1 from $\mathrm{EC} 2$ but $V_{\text {test }} / V_{\text {calc }}$ was less than 1 for all the beams tested by the authors. The percentage improvement in $V_{\text {test }} / V_{\text {calc }}$ owing to taking $a=0$ was similar for all the beams which was not the case when the concrete cylinder strength was limited to $50 \mathrm{MPa}$ in Equation 1 from EC2. The strengths calculated with $a=10 \mathrm{~mm}$ are theoretically appropriate for beams BG0 since the aggregate did not fracture. It is interesting to note that the $V_{\text {test }} / V_{\text {calc }}$ ratios obtained with the MCFT are very similar for beams BG0 and BL0 if $a$ is taken as $10 \mathrm{~mm}$ for the gravel and zero for the limestone beams, as implied by the observed behaviour.

\section{Beams with shear reinforcement \\ Experimental investigation}

Ten beams were tested to investigate the effect of varying the aggregate type, loading arrangement and shear reinforcement ratio on the shear strength and cracking pattern. Six continuous and four simply supported beams were tested. Figure 5 gives details of the loading arrangement for the continuous beams which were statically determinate with a point of contraflexure at the centre of the critical shear span. Table 3 and Figure 6 give details of the beam dimensions, material properties and reinforcement. The width of beams $C$ and D was increased to $160 \mathrm{~mm}$ to accommodate the $10 \mathrm{~mm}$ diameter stirrups used in these beams. The flexural reinforcement in the continuous beams consisted of two layers of $2 \mathrm{~T} 25$ bars placed at the top and bottom of the section to resist the anti-symmetric bending moment distribution shown in Figure 5(d). The corresponding flexural reinforcement ratios $\left(100 A_{\mathrm{sl}} / b s\right)$ were $3 \cdot 32 \%$ in beams $\mathrm{B}$ and $2 \cdot 80 \%$ in beams $\mathrm{C}$. A third layer of flexural reinforcement was provided in the simply supported D series to prevent flexural failure which reduced the effective depth $d$ from $437 \mathrm{~mm}$ to $412 \mathrm{~mm}$. The stirrup spacing in the critical shear spans varied between $90 \mathrm{~mm}$ and $300 \mathrm{~mm}$ as shown in Figure 6 which corresponds to stirrup ratios $\left(100 A_{\mathrm{sw}} /\right.$

\begin{tabular}{|c|c|c|c|c|c|c|}
\hline \multirow[t]{2}{*}{ Beam } & \multirow[t]{2}{*}{$V_{\text {test }}: \mathrm{kN}$} & \multirow[t]{2}{*}{$V_{\text {flex }}: k N$} & \multicolumn{2}{|c|}{ EC2 (Equation 1) } & \multicolumn{2}{|c|}{ MCFT: Response 2000} \\
\hline & & & $V_{\text {test }} / V_{\text {calc }}$ & $\begin{array}{c}V_{\text {test }} / V_{\text {calc }} \\
\left(f_{\mathrm{c}}^{\prime} \leqslant 50 \mathrm{MPa}\right)\end{array}$ & $\begin{array}{c}V_{\text {test }} / V_{\text {calc }} \\
(a=10 \mathrm{~mm})\end{array}$ & $\begin{array}{c}V_{\text {test }} / V_{\text {calc }} \\
(a=0)\end{array}$ \\
\hline BG0-1 & $61 \cdot 31$ & 100 & $0.76(1.14)$ & $0.89(1.33)$ & $0.88(1.34)$ & $0.94(1.44)$ \\
\hline BG0-2 & $63 \cdot 11$ & 100 & $0.78(1.17)$ & $0.92(1.37)$ & $0.91(1.38)$ & $0.97(1.48)$ \\
\hline BLO-1 & $46 \cdot 86$ & 98.5 & $0.61(0.91)$ & $0.68(1.02)$ & $0.71(1.08)$ & $0.76(1.16)$ \\
\hline \multirow[t]{3}{*}{ BLO-2 } & 54.07 & $98 \cdot 5$ & $0.71(1.06)$ & $0.78(1.18)$ & $0.82(1.25)$ & $0.88(1.34)$ \\
\hline & Avg. & BGO & $0.77(1.15)$ & $0.90(1.35)$ & $0.89(1.36)$ & $0.95(1.46)$ \\
\hline & & BLO & $0.66(0.98)$ & $0.73(1.09)$ & $0.76(1.16)$ & $0.82(1.25)$ \\
\hline
\end{tabular}

\section{Notes:}

Design values in parentheses calculated with (EC2: $\gamma_{c}=1 \cdot 5 ;$ CSA: $\left.\gamma_{c}=1.53\right)$.

Response 2000: base curve (Popovic-Thorenfeld-Collins), comp. softening (Vecchio and Collins, 1986), tension stiffening (Bentz, 2000), crack spacing (auto), $f_{\mathrm{ct}}$ and $\varepsilon_{\mathrm{c}}^{\prime}$ (auto) 


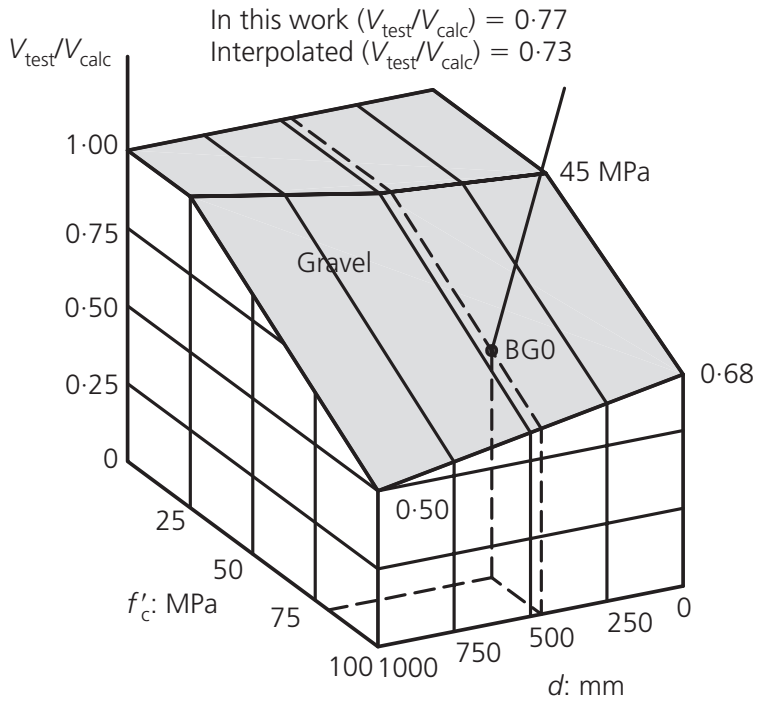

Point BGO ( $\left.d=465 \mathrm{~mm} ; f_{c}^{\prime}=80 \cdot 2 \mathrm{MPa}\right)$

(a)

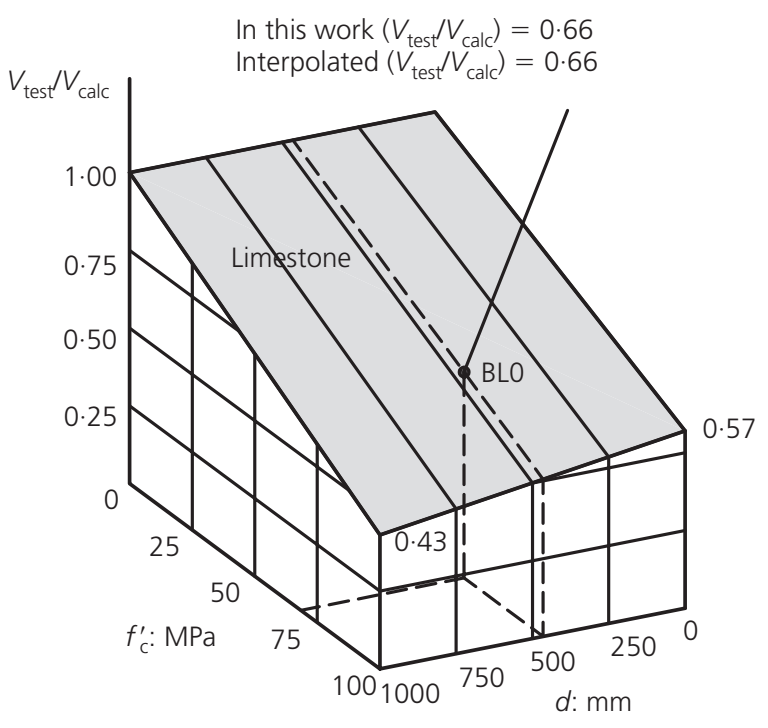

Point BLO ( $\left.d=465 \mathrm{~mm} ; f_{c}^{\prime}=68.4 \mathrm{MPa}\right)$

(b)

Figure 4. Comparison of $V_{\text {test }} / V_{\text {calc }}$ for $\mathrm{B} 0$ beams with predictions of Regan et al. (2005) (note: $V_{\text {calc }}$ is calculated with EC2 with no restriction on $f_{c}^{\prime}$ ): (a) gravel aggregate specimens; and (b) limestone aggregate specimens

$b s$ ) between $0 \cdot 33 \%$ and $0 \cdot 83 \%$. Sufficient shear reinforcement was provided in the shorter shear spans of the continuous beams to prevent shear failure. The shear reinforcement ratio and stirrup spacing were the same in the critical shear spans of the beams in the $\mathrm{C} 1$ and D1 series. Gravel aggregate was used in all the beams except the BL series in which limestone aggregate was used. The
$\mathrm{CA}, \mathrm{DA}, \mathrm{CB}$ and $\mathrm{DB}$ beams were cast together and can be regarded as duplicate sets $\mathrm{A}$ and $\mathrm{B}$. The $\mathrm{BL}$ and $\mathrm{BG}$ beams were intended to have the same concrete strength to assess the influence of aggregate type on shear strength. In reality, the concrete cylinder strength was significantly less in the BG (31.7 MPa) than the BL beams (53.1 MPa) which are comparable in strength to the CA and CB beams (49.35 MPa).

\section{Instrumentation}

Deflections were measured with linear variable differential transformers (LVDTs) and digital photogrammetry. Crack opening and sliding displacements were also derived from displacements measured between crosses of Demec points and LVDTs positioned as shown in Figure 5(a). The beams were pre-cracked before the instrumentation was positioned along the critical shear cracks. Transverse and longitudinal strains were also measured in the surface of the concrete between Demec points. Strains were measured in the flexural reinforcement in tests BG2 and BL2 at the position of maximum span moment.

\section{Test results}

Table 3 summarises the loads at failure and when shear cracks first formed. The maximum tensile strains in the flexural reinforcement were $1.79 \%$ and $2.5 \%$ respectively in beams BG2 and BL2, which were the most heavily loaded. Full details of the strain and displacement measurements are given elsewhere (Sagaseta, 2008). The shear cracks developed differently in the continuous and simply supported beams as shown in Figure 7 which highlights the critical shear cracks at failure. Figure 7 (a) shows that shear cracks initially formed near mid-height at $45^{\circ}$ in the simply supported beams and that, subsequently, additional shear cracks formed at flatter angles mobilising more stirrups. Strain measurements showed that the flatter cracks formed after the stirrups yielded. The 'crack rotation' evident in Figure 7(a) is well documented and is implicit in the plasticity truss used in EC2. The crack development was similar in all the continuous beams up to failure with little if any evidence of crack rotation. The shear cracks initially formed in the continuous beams around an effective depth from the loading points. Subsequently, additional cracks formed near the loading points in a fan shape as shown in Figures 7(b) and (c). Cracks only formed in the centre of the shear span in beams BG2, BL2, CA2 and CB2 towards the end of the test. The lack of crack rotation in the continuous beams would seem to suggest that aggregate interlock plays a greater part in transferring shear stresses through pre-existing cracks in simply supported than continuous beams.

The failure mode of the continuous beams was clearly influenced by the stirrup index $\mathrm{SI}=\rho_{\mathrm{w}} f_{\mathrm{y}} /\left(v f_{\mathrm{c}}^{\prime}\right)$ where $\rho_{\mathrm{w}}=A_{\mathrm{sw}} /(b s), s$ is the stirrup spacing and $v=0 \cdot 6\left(1-f_{\mathrm{c}}^{\prime} / 250\right)$. The failure of the beams with the lowest SI (CA1, CB1 and BL1) appears to have been triggered by loss of aggregate interlock resulting from the development of excessive strain in the stirrups crossing the critical diagonal crack. The critical shear crack in these beams (see Figure 7(b)) extended to the loading point, at the peak load, 


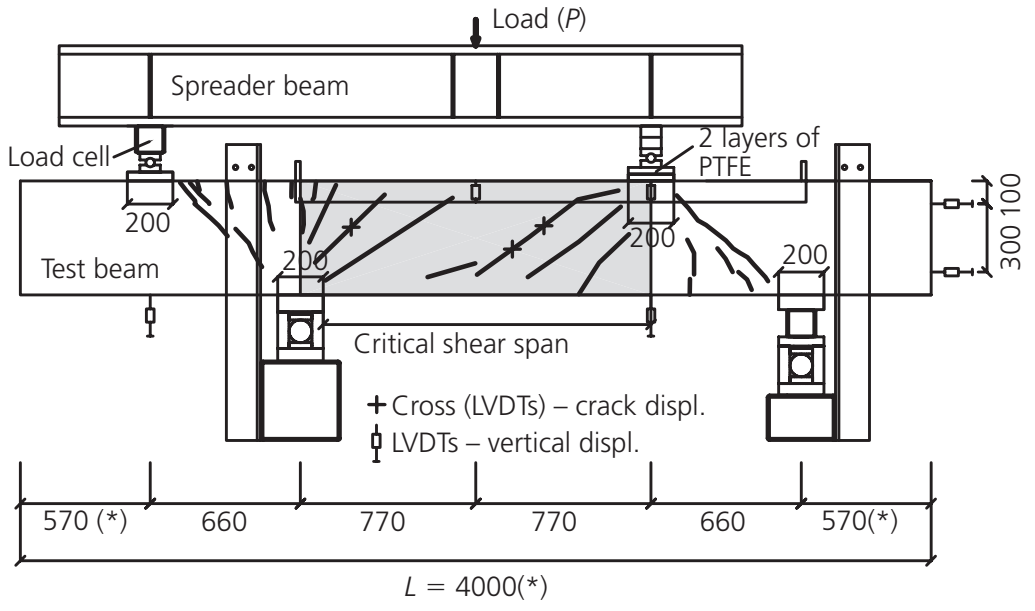

(a)

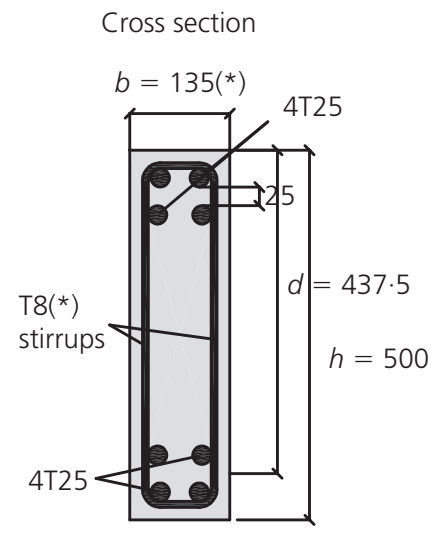

(b)

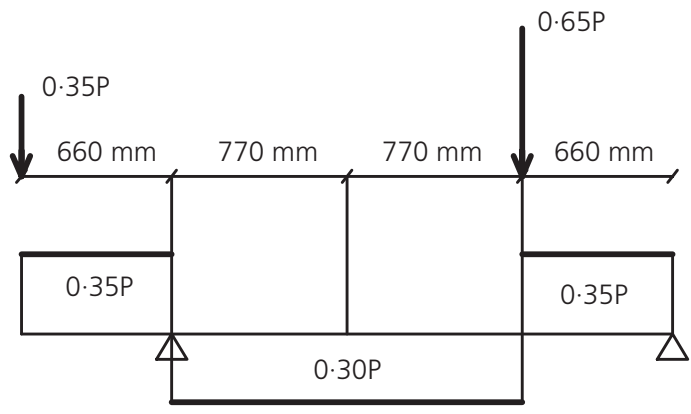

(c)

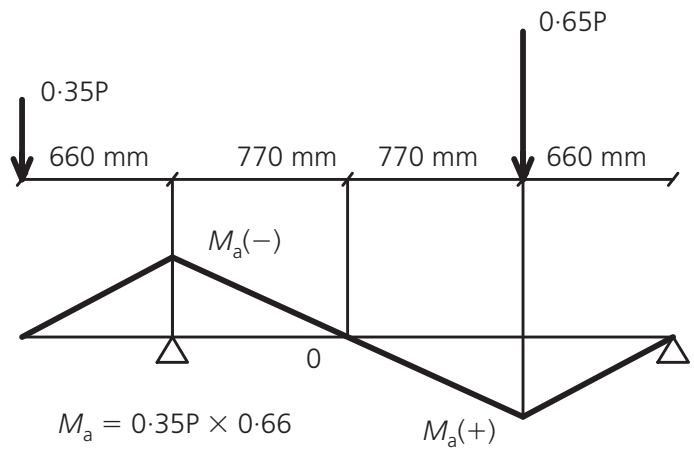

(d)

Figure 5. Loading arrangement for continuous beams: (a) testing rig; (b) cross-section; (c) shear force diagram; and (d) bending moment diagram. Notes: $\left.{ }^{*}\right)$ values for beams $B$; in beamc $C$ : $L=4500 \mathrm{~mm}, b=160 \mathrm{~mm}$ and $10 \mathrm{~mm}$ stirrups

and widened considerably under almost constant load. Beams CA2 and CB2 behaved similarly with several shear cracks widening simultaneously at failure (see Figure 7(c)). Reducing the stirrup spacing from $300 \mathrm{~mm}$ in beam CB1 to $200 \mathrm{~mm}$ in beam CB2 led to a significant reduction in the spacing of the inclined cracks as shown in Figure 7(c). The maximum width of the critical shear crack in beam $\mathrm{CB} 1$ was $1.2 \mathrm{~mm}$, which was approximately twice that in CB2. Beams BG2 and BL2 had the highest SI and failed in shear-compression. The diagonal strut split in the out-of plane direction in beam BL2 leading to the concrete spalling at the top and bottom of the beam. The main crack extended along the flexural reinforcement towards the ends of the beam immediately after failure in beams BG1 and BG2. Analysis of the beams in the next section provides no evidence that the longitudinal cracking, which is indicative of bond failure, precipitated failure. This conclusion is consistent with Hamadi and Regan's (1980) observation that bond failure frequently occurs in combination with shear failure.

\section{Analysis of test results}

\section{Influence of aggregate fracture}

Table 3 shows beams CA2 and CB2, with gravel aggregate, had similar concrete strengths and shear reinforcement ratios to beam BL1 with limestone aggregate. Aggregate fracture does not appear to have reduced the shear strength of beam BL1 since its shear strength $(V / b d=5.94 \mathrm{MPa})$ is very similar to that of beams CA2 (6.12 MPa) and CB2 (5.98 MPa). Interestingly, push-off tests (Sagaseta and Vollum, 2011) showed that significant shear stresses could be transferred through cracks in the limestone concrete even though the aggregate fractured. Sagaseta and Vollum (2011) has shown that significant shear stresses were 


\begin{tabular}{|c|c|c|c|c|c|c|c|c|c|}
\hline Loading & Beam & $f_{c}^{\prime}: M P a$ & $b: \mathrm{mm}$ & $\rho_{\mid}: \%$ & $\rho_{\mathrm{w}} f_{\mathrm{y}}: \mathrm{MPa}$ & $\delta_{\text {centre }}^{*}: \mathrm{mm}$ & $P_{\mathrm{cr}}: \mathrm{kN}$ & $P_{\text {ult }}: \mathrm{kN}$ & Failure mode \\
\hline \multirow{8}{*}{$\begin{array}{l}\text { Continuous beam } \\
(V=0 \cdot 3 P)\end{array}$} & $B G 1$ & $31 \cdot 70$ & 135 & $3 \cdot 32$ & $2 \cdot 73$ & $5 \cdot 29$ & 300 & $950 \cdot 6$ & $\operatorname{SC}(*)$ \\
\hline & $B G 2$ & $31 \cdot 70$ & 135 & $3 \cdot 32$ & $4 \cdot 55$ & $5 \cdot 43$ & 300 & $1074 \cdot 1$ & $C W(*)$ \\
\hline & BL1 & $53 \cdot 11$ & 135 & $3 \cdot 32$ & $2 \cdot 73$ & $4 \cdot 90$ & 400 & $1169 \cdot 1$ & CW \\
\hline & $\mathrm{BL} 2$ & $53 \cdot 11$ & 135 & $3 \cdot 32$ & 4.55 & 6.02 & 300 & $1593 \cdot 9$ & SC \\
\hline & CB1 & $49 \cdot 35$ & 160 & $2 \cdot 80$ & 1.96 & $3 \cdot 14$ & 400 & $1029 \cdot 3$ & $\mathrm{CW}$ \\
\hline & CB2 & $49 \cdot 35$ & 160 & $2 \cdot 80$ & 2.94 & $5 \cdot 99$ & 450 & $1429 \cdot 0$ & CW \\
\hline & CA1 & $49 \cdot 35$ & 160 & $2 \cdot 80$ & 1.96 & $4 \cdot 23$ & 400 & $979 \cdot 8$ & $\mathrm{CW}$ \\
\hline & CA2 & $49 \cdot 35$ & 160 & $2 \cdot 80$ & $2 \cdot 94$ & $4 \cdot 76$ & 450 & $1395 \cdot 5$ & $\mathrm{CW}$ \\
\hline Simply & DA1 & $49 \cdot 35$ & 160 & $4 \cdot 46$ & 1.96 & $14 \cdot 87$ & 200 & $622 \cdot 7$ & $\mathrm{CW}$ \\
\hline supported & DB1 & $49 \cdot 35$ & 160 & $4 \cdot 46$ & 1.96 & $13 \cdot 84$ & 200 & $598 \cdot 4$ & $\mathrm{CW}$ \\
\hline
\end{tabular}

\section{Notes:}

$f_{y}$ (stirrups) $=550 \mathrm{MPa} ; f_{y}$ (longitudinal) $=580 \mathrm{MPa}$

Failure modes: shear compression (SC); crack widening (CW)

${ }^{*}$ ) shear failure accompanied by bond failure

$\delta^{*}$ centre vertical deflection under the central load at failure load

$P_{\mathrm{cr}}$ load at which shear cracks were first observed

Table 3. Experimental data for beams with shear reinforcement

transferred through the cracks in beam BL2 despite the aggregate fracturing.

\section{Contribution of compression flange}

Figure 8 compares the shear strengths of the tested beams with the predictions of EC2 and the shear strengths of beams with rectangular, ' $\mathrm{T}$ '- and ' $\mathrm{I}$ '- shaped cross-sections tested by others. Figure 8 is similar to the figure used to demonstrate the validity of the EC2 design method in the background document for shear in EC2 (Walraven, 2004). The main difference between the figures is that Walraven (2004) only included data from 'I' and ' $T$ ' sections which fail at significantly higher shear stresses than the rectangular sections shown in Figure 8. The beams from Watanabe and Lee's (1998) database in Figure 8 were tested in Japan in the late 1980s and failed in shear. The beams were continuous and rectangular in cross-section with similar dimensions and flexural reinforcement ratios to the $\mathrm{B}$ and $\mathrm{C}$ series of beams tested in this programme. The concrete cylinder strengths varied between 20.4 MPa and 139.5 MPa. The yield strengths of the flexural $\left(870<f_{\mathrm{y}}<1070\right)$ and shear reinforcement $\left(225<f_{\mathrm{y}}<1478\right)$ were unusually high in these tests.

Figure 8 shows that the authors' results are broadly consistent with those of Watanabe and Lee (1998) despite the unusually high reinforcement strengths in the latter. The increased shear strength of the ' $\mathrm{T}$ ' and ' $\mathrm{I}$ ' beams, relative to the rectangular beams, is attributed to the contribution of the compression flange which can be estimated as follows (Placas, 1969)

2. $V_{\mathrm{cz}}=0 \cdot 1 f_{\mathrm{cu}}^{2 / 3}\left(b_{\mathrm{w}}+1 \cdot 5 \lambda h_{\mathrm{f}}\right) h_{\mathrm{f}}$ where

$$
\lambda=1 \cdot 0 \text { if }\left[\left(b_{\mathrm{f}}-b_{\mathrm{w}}\right)>3 h_{\mathrm{f}}\right]
$$

and

$$
\lambda=\left(b_{\mathrm{f}}-b_{\mathrm{w}}\right) / 3 h_{\mathrm{f}} \text { if }\left[\left(b_{\mathrm{f}}-b_{\mathrm{w}}\right)<3 h_{\mathrm{f}}\right]
$$

Equation 2 implies that the compression flange increased the shear strength of the ' $\mathrm{I}$ ' and ' $\mathrm{T}$ ' beams in Figure 8 by between $10 \%$ and $20 \%$. This estimate is consistent with the findings of Leonhardt and Walther (1961), Regan (1971) and Pansuk and Sato (2007) and is of the same order as the difference between the shear strengths of comparable flanged and rectangular sections in Figure 8. It is also striking that the shear strengths of the authors' simply supported beams DA1 and DB1 were very similar to those of the equivalent continuous beams CA1 and $\mathrm{CB} 1$. This suggests that the difference between the strengths of the rectangular and flanged sections in Figure 8 is principally attributable to the reduced contribution of the compression zone in the rectangular beams.

\section{Evaluation of shear strength with EC2}

The variable strut inclination (VSI) method in EC2 was used to assess the shear strength of all the rectangular beams in Figure 8. The VSI method is based on the work of Nielsen and Baestrup (1976) and Muttoni et al. (1989) among others. The method assumes that the shear force is resisted by a truss consisting of concrete struts equilibrated by shear reinforcement with $V_{\mathrm{c}}=0$. The angle between the concrete struts and the longitudinal axis of 


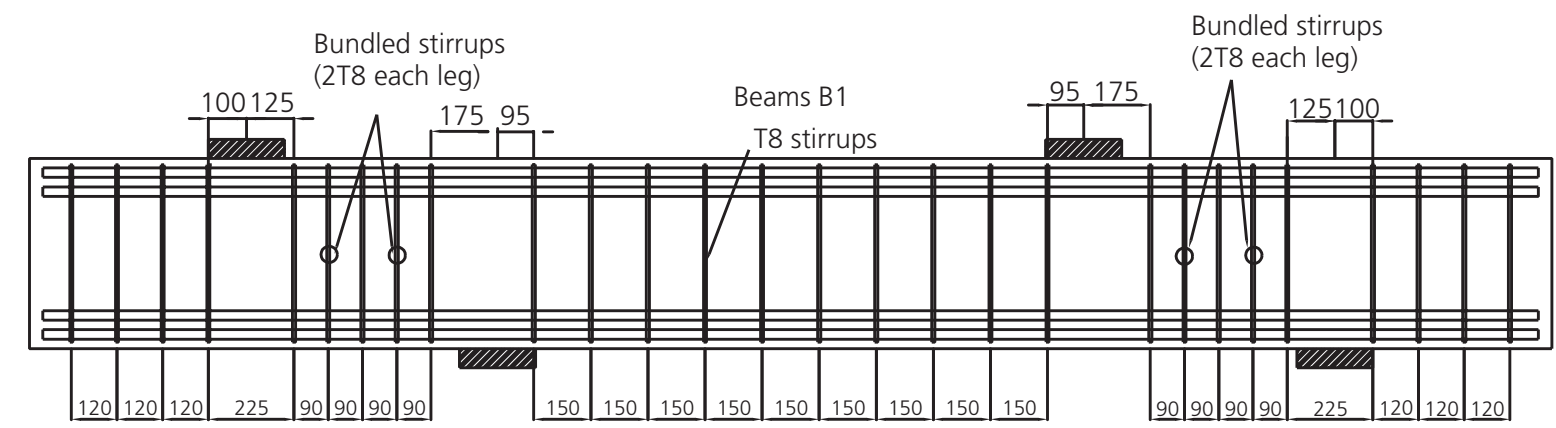

(a)

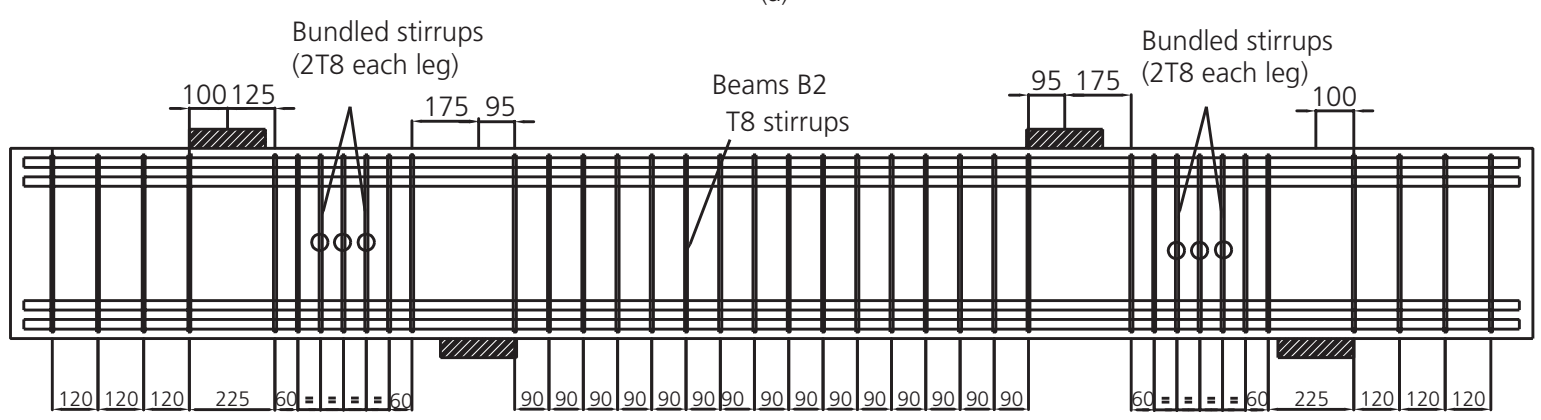

(b)

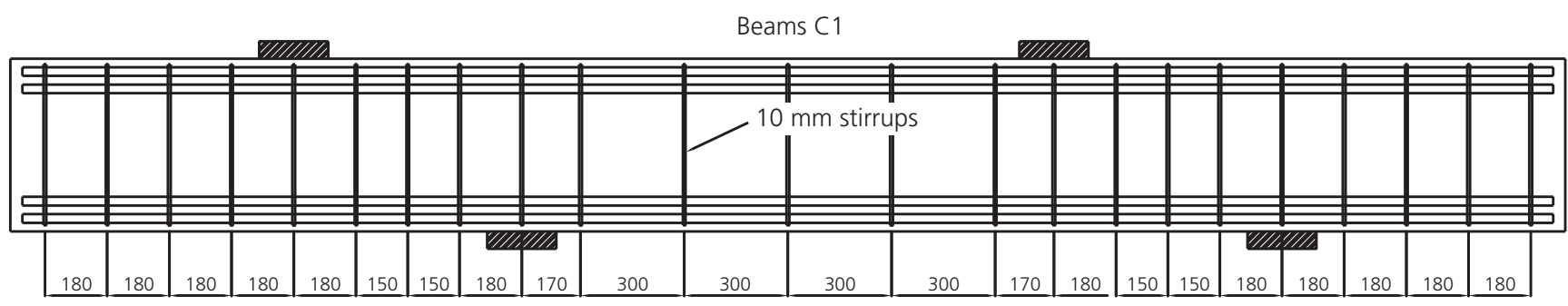

(c)

Beams C2

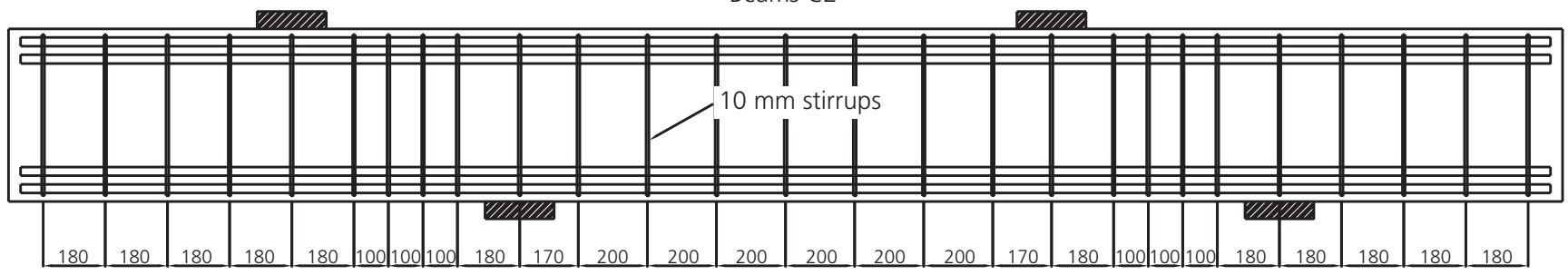

(d)

Figure 6. Reinforcement arrangement in continuous beams:

(a) beams BG1/BL1; (b) beams BG2/BL2; (c) beams CA1/CB1; and

(d) beams CA2/CB2

the beam is allowed to vary between $21 \cdot 8^{\circ}$ to $45^{\circ}$ depending upon the applied shear force. In reality, the angle of the compression field in the truss is steeper than assumed in EC2 as part of the shear force is resisted by $V_{\mathrm{c}}$. For members with vertical shear reinforcement, the design value of the shear strength is given by
3. $V_{\mathrm{Rd}, \mathrm{s}}=A_{\mathrm{sw}} z f_{\mathrm{ywd}} \cot \theta / s$

where $A_{\mathrm{sw}}$ is the area of shear reinforcement, $f_{\mathrm{ywd}}=f_{\mathrm{yk}} / \gamma_{\mathrm{s}}$ is the design yield strength of the shear reinforcement, $s$ is the stirrup 
Span $(L=1.52 \mathrm{~m})$

$\rho_{w}=0.33 \%$

$V=0.5 P$

$M_{\max } / V=1.52 \mathrm{~m}$

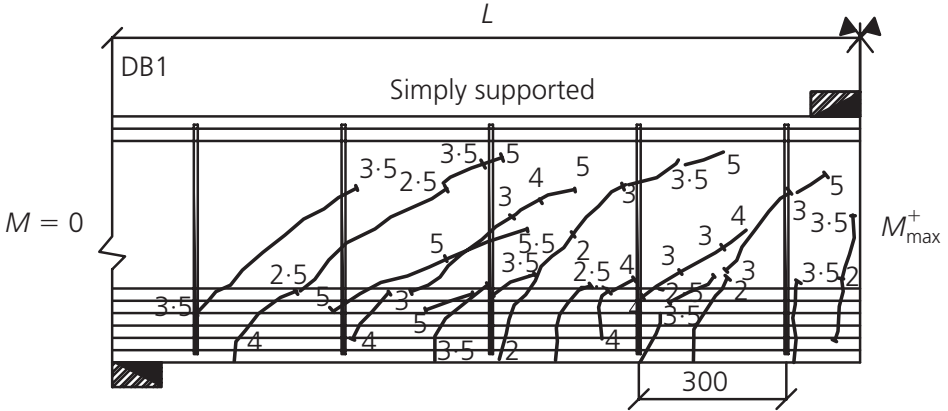

(a)

CB1

Continuous

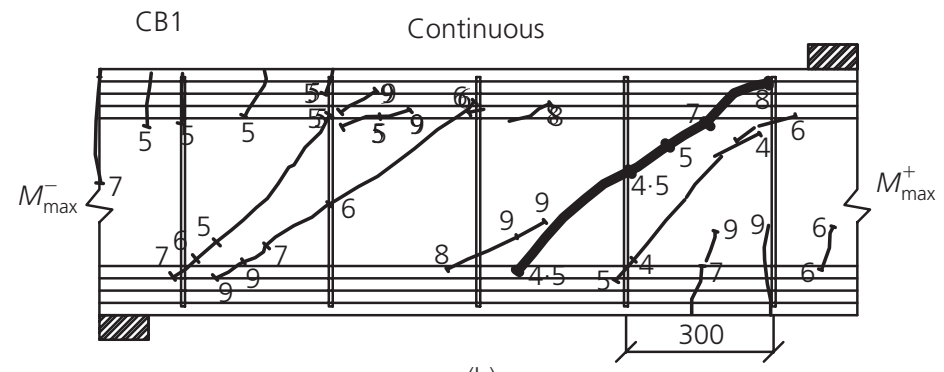

(b)

$$
\begin{aligned}
& \rho_{\mathrm{w}}=0.33 \% \\
& V=0.3 P \\
& M_{\max } / V=0.77 \mathrm{~m}
\end{aligned}
$$$$
\operatorname{span}(L=1.54 \mathrm{~m})
$$

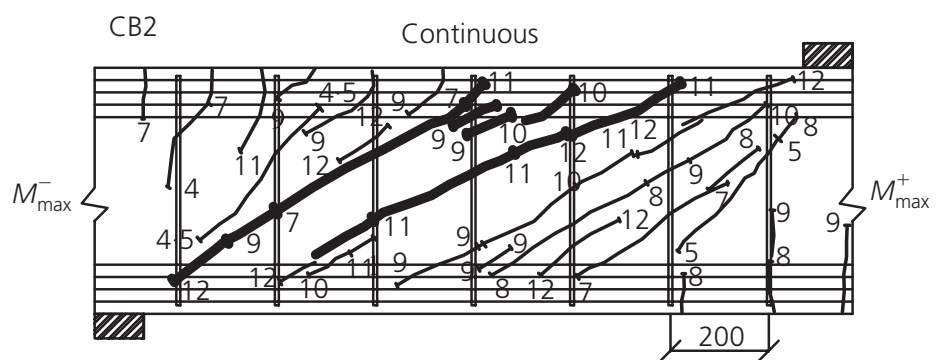

(c)
$\operatorname{Span}(L=1.54 \mathrm{~m})$

$\rho_{\mathrm{w}}=0.49 \%$

$V=0.3 P$

$M_{\max } / V=0.77 \mathrm{~m}$

Figure 7. Typical crack pattern in beams: (a) DB1 (simply

supported); (b) CB1 (continuous); and (c) CB2 (continuous).

Note: numbers refer to load $(\times 100 \mathrm{kN})$ at which cracks were

first observed

spacing, $\theta$ is the angle between the compressive stress field and the longitudinal axis of the beam, $1 \leqslant \cot \theta \leqslant 2.5$ and $z$ is the lever arm for shear for which EC2 recommends a value of $0.9 d$. EC2 defines the maximum shear capacity as follows for beams with vertical stirrups

$$
\text { 4. } \quad V_{\mathrm{Rd}, \max }=b_{\mathrm{w}} z v f_{\mathrm{cd}} /(\cot \theta+\tan \theta)
$$

where $v=0.6\left(1-f_{\mathrm{ck}} / 250\right)$ is a strength reduction factor for concrete with skew cracks and $f_{\mathrm{cd}}=f_{\mathrm{ck}} / \gamma_{\mathrm{c}}$ is the design concrete strength.

Table 4 shows that the shear strengths of the tested beams were typically less than predicted by EC2 with $z=0 \cdot 9 d$ and partial material factors $\gamma_{\mathrm{c}}$ and $\gamma_{\mathrm{s}}=1.0$. For example, the shear strengths of beams BG1 and BG2, for which $\cot \theta$ is less than $2 \cdot 5$, are overestimated by $15 \%$ and $22 \%$ respectively. Figure 8 shows that EC2 systematically underestimates the shear strength of rectangular beams with $\mathrm{SI}=\rho_{\mathrm{w}} f_{\mathrm{y}} / v f_{\mathrm{c}}^{\prime}>\sim 0.05$ when the material partial factors equal 1 . However, EC2 gives a reasonable lower bound to the test data when shear strengths are calculated with partial factors of $\gamma_{c}=1.5$ for concrete and $\gamma_{\mathrm{s}}=1 \cdot 15$ for steel.

\section{Comparison of shear strength predictions of EC2,} BS 8110, MCFT and CSA A.23.3-04

The relative performance of the design methods in EC2, BS 8110 and CSA A.23.3-04 (CSA, 2004) was evaluated, with and without material partial factors, for the beams tested in this programme 


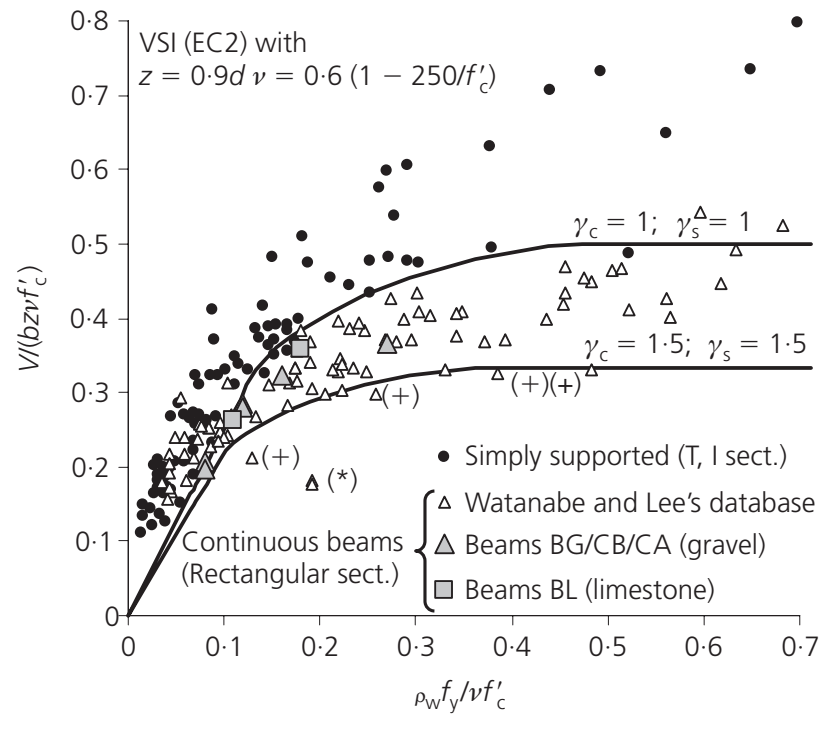

Figure 8. Comparison of test data with shear strengths calculated with EC2 for simply supported beams with ' $T$ ' and ' $I$ ' sections and continuous beams with rectangular sections. Tests marked with ${ }^{*}$ ) failed prematurely due to bonding. Tests marked with (+) had a very high concrete strength $f_{c}^{\prime}=140 \mathrm{MPa}$. Simply supported beams: Sörensen (1974), Regan and Reza-Jorabi (1987), Placas (1969), Leonhardt and Walther (1961), Moayer and Regan (1974), Hamadi and Regan (1980), Muhidin and Regan (1977), Levi and Marro (1993), Walraven and Stroband (1999)

and 62 continuous beam tests from Figure 8 where sufficient data were available to apply the CSA method. The shear strength of the authors' beams was also calculated with the MCFT using Response 2000 (Bentz, 2000). The 62 beams consisted of 54 from Watanabe and Lee's database (Watanabe and Lee, 1998), seven from the normal-weight concrete tests by Ramirez et al. (2004) and one from Regan (1971). The concrete cylinder strengths in the 62 beam tests considered varied from $21.2 \mathrm{MPa}$ to $75 \cdot 2 \mathrm{MPa}$. The maximum possible design shear strength was taken as $0.8 \mathrm{~V} f_{\mathrm{cu}}$ in BS 8110 but not more than $8 \mathrm{MPa}$ as recommended in Concrete Society technical report 49 (Concrete Society, 1998).

Table 4 presents results for the beams tested in this programme. It shows that the MCFT predicted the strengths most accurately and BS 8110 most conservatively. As expected, the predictions of CSA A.23.3-04 were more conservative than the rigorous implementation of the MCFT in Response 2000 (Bentz, 2000). Reducing the aggregate size to zero in Response 2000 only reduced the predicted strength of the BL beams with limestone aggregate by around $2 \%$ since the concrete component of shear resistance $\left(V_{\mathrm{c}}\right)$ was relatively small compared with the stirrup component $\left(V_{\mathrm{s}}\right)$. These results are consistent with the authors' test data which, as previously discussed, show no noticeable influence of aggregate fracture on the shear strengths of beams with shear reinforcement.
Figures 9(a) and 9(b) show results for all the beams with material partial factors equal to 1 . The figures show that BS 8110 and CSA A.23.3-04 performed reasonably well independently of the stirrup index but EC2 overestimated the strength of a significant number of beams. Figure 9(c) suggests that the accuracy of the shear strength predictions is relatively independent of the stirrup yield strength for strengths as high as $1478 \mathrm{MPa}$. Table 5(a) shows that EC2 (with $\gamma_{\mathrm{c}}=\gamma_{\mathrm{s}}=1.0$ ) underestimates the strength of $67 \%$ of the beams with SI $<0.5$ which is the maximum SI at which stirrups yield in EC2. Furthermore, BS 8110 and CSA A.23.3-04 performed significantly better giving similar values for $V_{\text {test }} / V_{\text {calc }}$. Table 5(a) and Figure 9 also show that the EC2 predictions improve significantly for SI $>0.05$ if the lever arm $z$ is taken as $0 \cdot 8 d$ in Equations 3 and 4 . The corresponding flexural lever arms were calculated for comparison using the rectangular parabolic stress block in EC2 and were found to be $0.86 \mathrm{~d}$ for the $\mathrm{BL}$ and $\mathrm{BG}$ beams. The mean flexural lever arm was $0 \cdot 84 d$ for the beams of Watanabe and Lee (1998) with a coefficient of variation of $2 \cdot 4 \%$.

\section{Comparison of design shear strengths}

A direct comparison of the shear capacities without partial factors is somewhat misleading since their effect varies between the codes and depends on the proportion of shear stress resisted by the shear reinforcement. For example, the shear strength is independent of the concrete strength in EC2 if $\cot \theta=2 \cdot 5$, and is only reduced by the multiple $1 / \gamma_{s}=0.87$ (where $\gamma_{\mathrm{s}}$ is the partial factor for steel) when partial material factors are introduced. The reduction in strength due to partial factors can be significantly greater in CSA A.23.3-04 and BS 8110 since $V_{\mathrm{c}}$ reduces by multiples of 0.65 and 0.8 respectively. Therefore, notional overall FOS equal to $V_{\text {test }} / V_{\text {design }}$ (where $V_{\text {design }}$ is the design ultimate shear resistance divided by the overall load factor) were calculated for all the continuous beams in Figure 9 using EC2, BS 8110 and CSA A.23.3-04 assuming equal dead and imposed loads. The results are plotted against the stirrup index in Figure 10 which lists the partial load and material factors used for each code. Table 5(b) shows that EC2 gives significantly lower FOS than BS 8110 or CSA A.23.3-04 for $0.05<\mathrm{SI}<0.25$ if $z$ is taken as $0 \cdot 9 d$ as recommended in the code.

Influence of flexural reinforcement ratio on design shear strength

Shear strengths calculated with EC2 are independent of the flexural reinforcement ratio $\left(\rho_{1}=A_{\mathrm{s}} / b d\right)$ for beams with shear reinforcement unlike strengths calculated with BS 8110 or CSA A.23.3-04. Shear strengths calculated with CSA A.23.3-04 reduce with increasing strain in the flexural reinforcement at the critical section, which is typically at a distance $d$ from the loading point for the beams considered in this paper. Figure 9(d) shows the influence of the longitudinal strain at the mid-height of the critical section (as defined in CSA A.23.3-04) on $V_{\text {test }} / V_{\text {calc }}$ for EC2 and CSA A.23.3-04. Figure 9(d) suggests that EC2 may progressively overestimate shear strength as a result of neglecting the influence of longitudinal strain but this was not the case for 


\begin{tabular}{|c|c|c|c|c|c|c|c|c|}
\hline \multirow[t]{2}{*}{ Beam } & \multirow[t]{2}{*}{$\mathrm{SI}=\rho_{\mathrm{w}} f_{\mathrm{y}} / v f_{\mathrm{c}}^{\prime}$} & \multirow[t]{2}{*}{$V_{\text {test }}: \mathrm{kN}$} & \multicolumn{2}{|c|}{ VSI (EC2) } & \multirow{2}{*}{$\begin{array}{l}\text { BS } 8110 \\
V_{\text {test }} / V_{\text {calc }}\end{array}$} & \multirow{2}{*}{$\begin{array}{c}\text { Resp. } \\
2000 \\
V_{\text {test }} / V_{\text {calc }}\end{array}$} & \multicolumn{2}{|c|}{ MCFT (CSA) } \\
\hline & & & $V_{\text {test }} / V_{\text {calc }}$ & $\cot \theta$ & & & $V_{\text {test }} / V_{\text {calc }}$ & $\cot \theta$ \\
\hline BG1 & $0 \cdot 16$ & $285 \cdot 19$ & 0.87 & $2 \cdot 26$ & $1 \cdot 19$ & 0.98 & 1.04 & $1 \cdot 49$ \\
\hline BG2 & 0.27 & $322 \cdot 24$ & 0.82 & 1.63 & 0.93 & 0.82 & 0.84 & $1 \cdot 38$ \\
\hline BL1 & 0.11 & $350 \cdot 73$ & 0.97 & $2 \cdot 50$ & $1 \cdot 38$ & 1.06 & $1 \cdot 22$ & $1 \cdot 48$ \\
\hline BL2 & $0 \cdot 18$ & $478 \cdot 18$ & 0.93 & $2 \cdot 13$ & $1 \cdot 32$ & 1.04 & $1 \cdot 22$ & $1 \cdot 38$ \\
\hline CA1 & 0.08 & $293 \cdot 96$ & 0.95 & $2 \cdot 50$ & $1 \cdot 21$ & 0.97 & 1.09 & $1 \cdot 49$ \\
\hline CB1 & 0.08 & $308 \cdot 80$ & 1.00 & $2 \cdot 50$ & $1 \cdot 27$ & 1.02 & $1 \cdot 14$ & 1.49 \\
\hline CA2 & $0 \cdot 12$ & $418 \cdot 66$ & 0.90 & $2 \cdot 50$ & $1 \cdot 34$ & 1.07 & $1 \cdot 23$ & $1 \cdot 42$ \\
\hline CB2 & 0.12 & $428 \cdot 71$ & 0.93 & $2 \cdot 50$ & $1 \cdot 38$ & 1.09 & $1 \cdot 25$ & 1.42 \\
\hline DA $1 *$ & 0.08 & $311 \cdot 37$ & 1.07 & $2 \cdot 50$ & $1 \cdot 35$ & 1.07 & $1 \cdot 29$ & $1 \cdot 43$ \\
\hline \multirow[t]{4}{*}{$\mathrm{DB} 1$ * } & 0.08 & $299 \cdot 22$ & 1.03 & $2 \cdot 50$ & $1 \cdot 29$ & 1.02 & $1 \cdot 24$ & 1.43 \\
\hline & & Avg. & 0.95 & & $1 \cdot 27$ & 1.01 & $1 \cdot 16$ & \\
\hline & & SD & 0.07 & & 0.13 & 0.08 & 0.14 & \\
\hline & \multicolumn{2}{|c|}{ COV: \% } & $7 \cdot 81$ & & $10 \cdot 65$ & 8.03 & $11 \cdot 75$ & \\
\hline
\end{tabular}

Notes:

* All beams continuous except DA1 and DB1

No partial material factors were applied

EC2 (VSI), $z=0.9 d$

BS 8110, the cube strength was taken as $1.25 f_{c}^{\prime}$ with no limitation on $f_{\mathrm{cu}}$

MCFT: Response 2000, base curve (Popovics-Thorenfeldt-Collins); comp. softening (Vecchio and Collins, 1986); tens. stiffening (Bentz, 2000); aggregate size $10 \mathrm{~mm}$; no strain hardening considered for steel

MCFT: CSA, crack spacing $s_{\mathrm{ze}}=300 \mathrm{~mm} ; M_{f} \geqslant V d_{\mathrm{v}}$

Table 4. Measured and predicted shear strengths for beams with

shear reinforcement (bold type signifies that $V_{\text {test }} / V_{\text {calc }}$ is less than 1)

the authors' continuous beams, which are highlighted in Figure 9(d). It is, however, striking that the critical shear cracks in the authors' tests (see Figure 7) passed through the critical section assumed in CSA A.23.3-04 at $d$ from the loading point. Further tests, in which just the area of flexural reinforcement is varied, are required to establish the influence of axial strain definitively.

The influence of the flexural reinforcement ratio on the code predictions was explored in a series of parametric studies on continuous beams with the dimensions used in the tests of (a) Ramirez et al. (2004) (with $f_{\text {ck }}=46 \mathrm{MPa}$ ) and (b) this programme (with $f_{\text {ck }}=40 \mathrm{MPa}$ ). The concrete strengths were chosen to be representative of those used in the corresponding test programmes. The following analyses were made for beams with each configuration. First, the flexural reinforcement was designed to yield at the design ultimate load which was assumed to be governed by the shear strength calculated with EC2. Second, the area of flexural reinforcement was increased by a multiple of 2 to replicate tests in which excess flexural reinforcement is provided. Third, shear strengths were calculated with the flexural reinforcement ratio of $100 A_{\mathrm{sl}} / b d=3.3$ used in the $\mathrm{BG}$ and $\mathrm{BL}$ beams tested in this programme.

The results (for $\gamma_{\mathrm{c}}=\gamma_{\mathrm{s}}=1 \cdot 0$ ) are presented in Figures 11(a) and 11(b) along with test data from Ramirez et al. (2004) and this programme. The figures show that the difference between the EC2 and CSA A.23.3-04 predictions depends on the strain in the flexural reinforcement and is greatest when (a) the area of reinforcement provided for flexure equals that required for strength and (b) the calculated value of $\cot \theta$ equals 2.5 in EC2 (i.e. when $\mathrm{SI}=\rho_{\mathrm{w}} f_{\mathrm{y}} / v f_{\mathrm{c}}^{\prime} \sim 0 \cdot 14$ ). Figure 11(a) shows that EC2 predicts the shear strength of the Ramirez et al. (2004) beams, in which SI $=\rho_{\mathrm{w}} f_{\mathrm{y}} / v f_{\mathrm{c}}^{\prime}$ was less than $0 \cdot 1$, reasonably well. Figure 11(b) shows that EC2 tends to overestimate the shear strength of the authors' beams which were more heavily reinforced in shear and that furthermore the strength increased almost linearly in proportion with $\mathrm{SI}=\rho_{\mathrm{w}} f_{\mathrm{y}} / v f_{\mathrm{c}}^{\prime}$ as predicted by CSA A.23.3-04. Figure 11(b) shows that the MCFT (Response 2000) accurately predicts the influence of SI on the shear strength of the tested beams with the exception of beam BG2 which had a surprisingly low strength. The inset to Figure 11(b) shows that the orientation of the inclined compressive stress field assumed in EC2 is typically skew to the cracks. It follows that the validity of the VSI model in EC2 is dependent on shear stresses being transferred through the crack. Sagaseta (2008) has shown that the trend of test data in Figure 11(b) is consistent with the predictions of the EC2 design model if the compressive strength of the concrete in the inclined stress field is limited by shear transfer through the cracks as illustrated diagrammatically in Figure 11(b). 


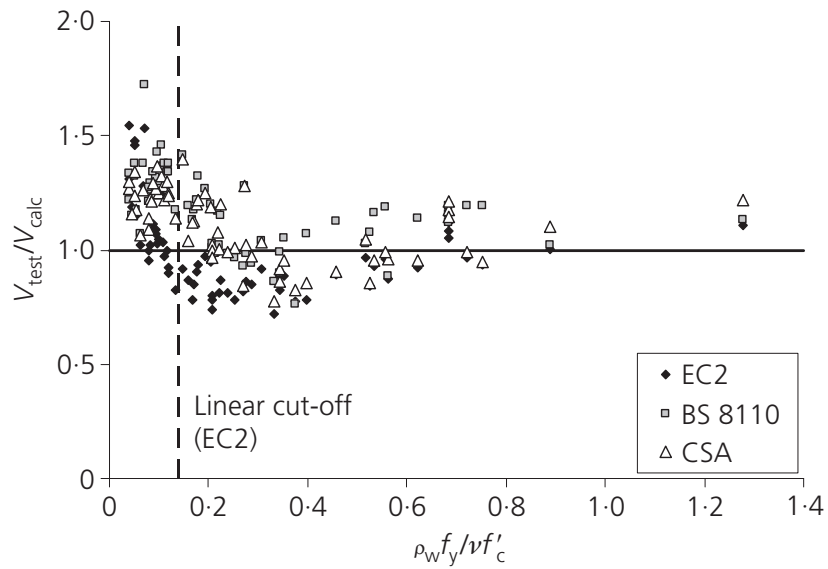

(a)

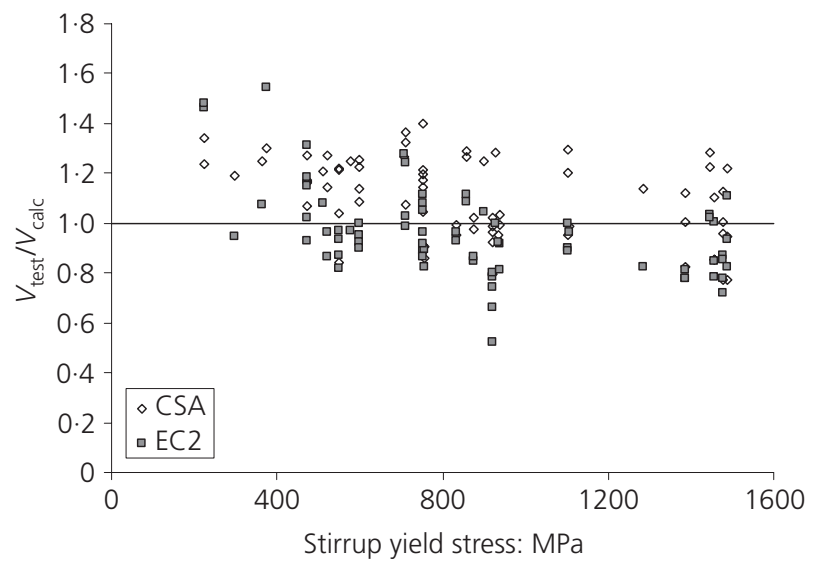

(c)

Figure 9. Comparison of test data with shear strengths calculated with EC2, BS 8110 and CSA for 62 continuous beams $\left(\gamma_{c}=\gamma_{s}=1.0\right)$ : (a) all beams (Watanabe and Lee (1998), Ramirez et al. (2004), Regan (1971) and continuous beams tested in this work); (b) practical subset of data from (a); (c) influence of stirrup yield strength on $V_{\text {test }} / V_{\text {calc }}$; and (d) influence of mid-height axial strain on $V_{\text {test }} / V_{\text {calc }}$

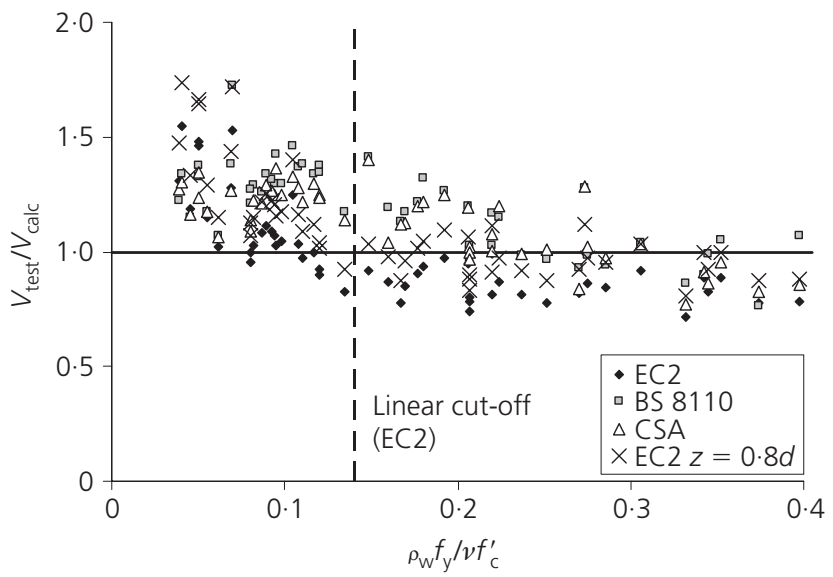

(b)

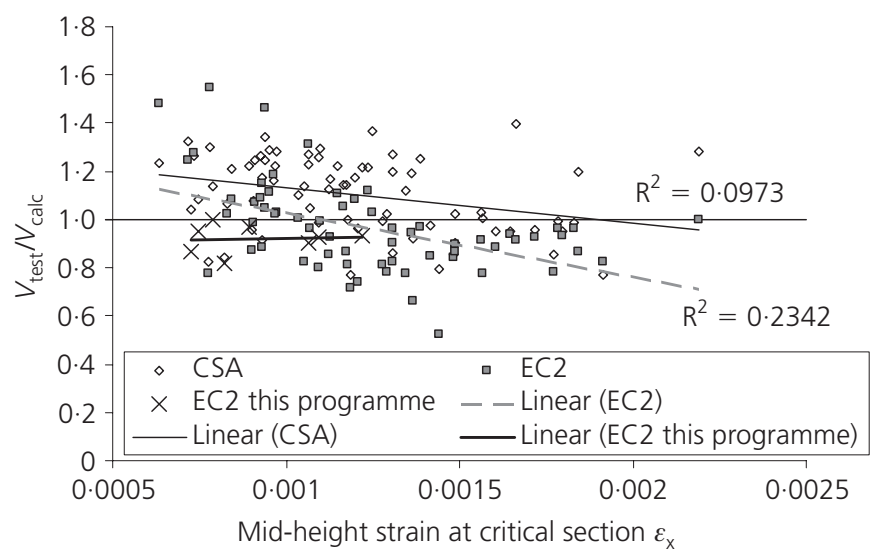

(d)
Figure 12 shows maximum permissible (i.e. unfactored) design shear stresses calculated with each code for the beam considered in Figure 11(b). The permissible shear stresses were calculated for equal dead and imposed loads with the load factors appropriate to each code listed below Figure 10. The area of flexural reinforcement was taken as (a) $A_{\text {sreq }}$, (b) $2 A_{\text {sreq }}$ and (c) $A_{\mathrm{s}}=0.033 b d$. Figure 12 (a) shows that BS 8110 and CSA A.23.304 tend to give significantly lower permissible shear stresses than EC2 with $z=0 \cdot 9 d$ when $A_{\text {sprov }}=A_{\text {sreq }}$ (where $A_{\text {sprov }}$ is the area of flexural reinforcement provided and $A_{\text {sreq }}$ is the area required for strength) and $\mathrm{SI}=\rho_{\mathrm{w}} f_{\mathrm{y}} / v f_{\mathrm{c}}^{\prime}>0.05$. Conversely, Figure 12(b) (with $A_{\mathrm{S}} / b d=3.3 \%$ ) shows that EC2 (with $z=0.9 d$ ) can give lower design shear strengths than CSA A.23.3-04 or BS 8110 when SI $<0.05$.

\section{Design recommendations for EC2}

The EC2 design method for shear is safe for all the beams in Figure 10 in the sense that the minimum FOS (calculated with mean material strengths) is greater than the mean load factor of 1.43. It is, however, striking that EC2 gives significantly lower FOS for shear than BS 8110 or CSA A.23.3-04. The authors believe that the FOS should be greater for shear than flexural failure, when the areas of shear and flexural reinforcement equal that required for strength, owing to the sudden and potentially catastrophic nature of shear failure. CSA A.23.3-04 appears to share this philosophy (Collins et al., 2008).

The FOS for flexural failure in EC2 (FOS $=M_{\text {test }} / M_{\text {design }}$ where $M_{\text {design }}$ is the design ultimate moment of resistance divided by the 


\begin{tabular}{|c|c|c|c|c|c|c|c|c|c|}
\hline \multirow{2}{*}{$\begin{array}{l}V_{\text {test }} / V_{\text {calc }} \\
\text { Code }\end{array}$} & \multirow{2}{*}{$\begin{array}{l}\mathrm{SI}<0.5 \\
\%<1.0^{+}\end{array}$} & \multicolumn{2}{|c|}{$\mathrm{SI}<0.05$} & \multicolumn{2}{|c|}{$0.05<\mathrm{SI}<0.14$} & \multicolumn{2}{|c|}{$0.14<\mathrm{SI}<0.25$} & \multicolumn{2}{|c|}{$0.25<\mathrm{SI}<0.5$} \\
\hline & & Mean & Cov & Mean & Cov & Mean & Cov & Mean & Cov \\
\hline EC2 & 67 & $1 \cdot 35$ & 0.14 & 1.08 & 0.17 & 0.87 & 0.09 & 0.85 & 0.09 \\
\hline $\begin{array}{l}E C 2, \\
\qquad z=0.8 d\end{array}$ & 38 & 1.52 & 0.14 & $1 \cdot 21$ & 0.17 & 0.97 & 0.09 & 0.95 & 0.09 \\
\hline CSA & 22 & $1 \cdot 24$ & 0.06 & $1 \cdot 23$ & 0.06 & $1 \cdot 12$ & 0.11 & 0.94 & $0 \cdot 14$ \\
\hline BS 8110 & 18 & $1 \cdot 24$ & 0.08 & $1 \cdot 31$ & $0 \cdot 10$ & $1 \cdot 15$ & 0.11 & 0.99 & 0.13 \\
\hline
\end{tabular}

Note: ${ }^{+} \%$ of specimens with $V_{\text {test }} / V_{\text {calc }}<1.0$ for $\mathrm{SI}<0.5$

Table 5a. Statistical analysis of data in Figure 9 for beams with SI $<0.5\left(\gamma_{c}=\gamma_{s}=1.0\right)$

\begin{tabular}{|c|c|c|c|c|c|c|c|c|c|c|}
\hline \multirow{2}{*}{$\begin{array}{l}\text { FOS } \\
\text { Code }\end{array}$} & \multirow{2}{*}{$\begin{array}{c}\mathrm{SI}<0.5 \\
\text { Min }\end{array}$} & \multirow{2}{*}{$\begin{array}{c}\mathrm{SI}<0.5 \\
\%<1.64^{*}\end{array}$} & \multicolumn{2}{|c|}{$\mathrm{SI}<0.05$} & \multicolumn{2}{|c|}{$0.05<\mathrm{SI}<0.14$} & \multicolumn{2}{|c|}{$0.14<\mathrm{SI}<0.25$} & \multicolumn{2}{|c|}{$0.25<\mathrm{SI}<0.5$} \\
\hline & & & Mean & Cov & Mean & Cov & Mean & Cov & Mean & Cov \\
\hline EC2 & $1 \cdot 42$ & 35 & $2 \cdot 21$ & $0 \cdot 14$ & $1 \cdot 79$ & 0.16 & $1 \cdot 67$ & 0.09 & $1 \cdot 72$ & 0.09 \\
\hline $\begin{array}{l}E C 2, \\
\qquad z=0.8 d\end{array}$ & $1 \cdot 60$ & 5 & $2 \cdot 48$ & $0 \cdot 14$ & $2 \cdot 02$ & $0 \cdot 16$ & 1.89 & 0.09 & 1.93 & 0.09 \\
\hline CSA & $1 \cdot 45$ & 16 & $2 \cdot 11$ & 0.07 & $2 \cdot 04$ & 0.07 & $1 \cdot 80$ & 0.11 & $1 \cdot 73$ & $0 \cdot 10$ \\
\hline BS 8110 & $1 \cdot 44$ & 5 & $2 \cdot 21$ & 0.05 & $2 \cdot 34$ & $0 \cdot 10$ & $2 \cdot 03$ & 0.11 & $1 \cdot 85$ & $0 \cdot 13$ \\
\hline
\end{tabular}

Note: * percentage of specimens with FOS $<1.64$

Table 5b. Statistical analysis of data in Figure 10 (with partial load and material factors) for beams with $\mathrm{SI}<0.5$

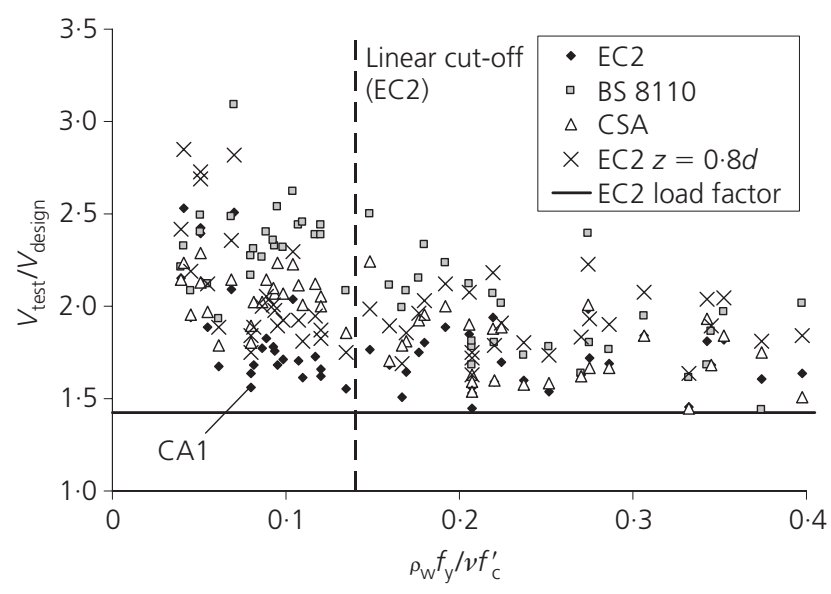

Figure 10. Overall factors of safety $\left(V_{\text {test }} / V_{\text {design }}\right)$ for continuous beams from Figure 9 calculated with EC2, BS 8110 and CSA. Notes: Design values assumed. Materials factors of safety $\left(\gamma_{\mathrm{C}} / \gamma_{\mathrm{S}}\right)$ : EC2 (1.5/1.15); BS 8110 (1.25/1.05); CSA (1.54/1.18). Load factors of safety (dead load = live load): EC2 $(1 \cdot 35+1 \cdot 5) / 2$; BS $8110(1.4+1 \cdot 6) / 2 ;$ CSA $(1 \cdot 25+1 \cdot 5) / 2$ overall load factor) is at least $1 \cdot 15(1 \cdot 35+1 \cdot 5) / 2=1 \cdot 64$ for equal dead and imposed loads and greater if allowance is made for the effects of (a) strain hardening and (b) the difference between the design and actual flexural lever arms. Therefore, it is concerning that the EC2 FOS for shear (with $z=0.9 d$ ) is below 1.64 for $35 \%$ of the beams in Figure 10 with SI $<0.5$ compared with $5 \%$ for BS 8110 and $16 \%$ for CSA A.23.3-04 (see Table 5(b)). It should also be noted that the shear strengths of many of the beams in Figure 10 may have been increased by the provision of surplus flexural reinforcement though further tests are required to confirm this.

Therefore, the authors propose that the EC2 FOS for shear should be increased for sections without compression flanges by reducing the lever arm for shear $z$. They propose that $z$ should be taken as $0.9 d$ for $\rho_{\mathrm{w}} f_{\mathrm{y}} / v f_{\mathrm{c}}^{\prime} \leqslant 0.025,0 \cdot 8 d$ for $\rho_{\mathrm{w}} f_{\mathrm{y}} / v f_{\mathrm{c}}^{\prime} \geqslant 0.05$, for sections without compression flanges, and be calculated by Iinear interpolation for intermediate values of $\rho_{\mathrm{w}} f_{\mathrm{y}} / v f_{\mathrm{c}}^{\prime}$. Figures 9 and 10 and Tables 5(a) and 5(b) show that this recommendation significantly improves the EC2 shear strength predictions for the rectangular beams studied in this paper. The effect of the proposed amendment is illustrated in Figures 11 and 12 which show that the proposed amendment to EC2 still allows greater shear strengths than CSA A.23.3-04 or BS 8110 when $A_{\text {sprov }}=A_{\text {sreq }}$ for flexure. 


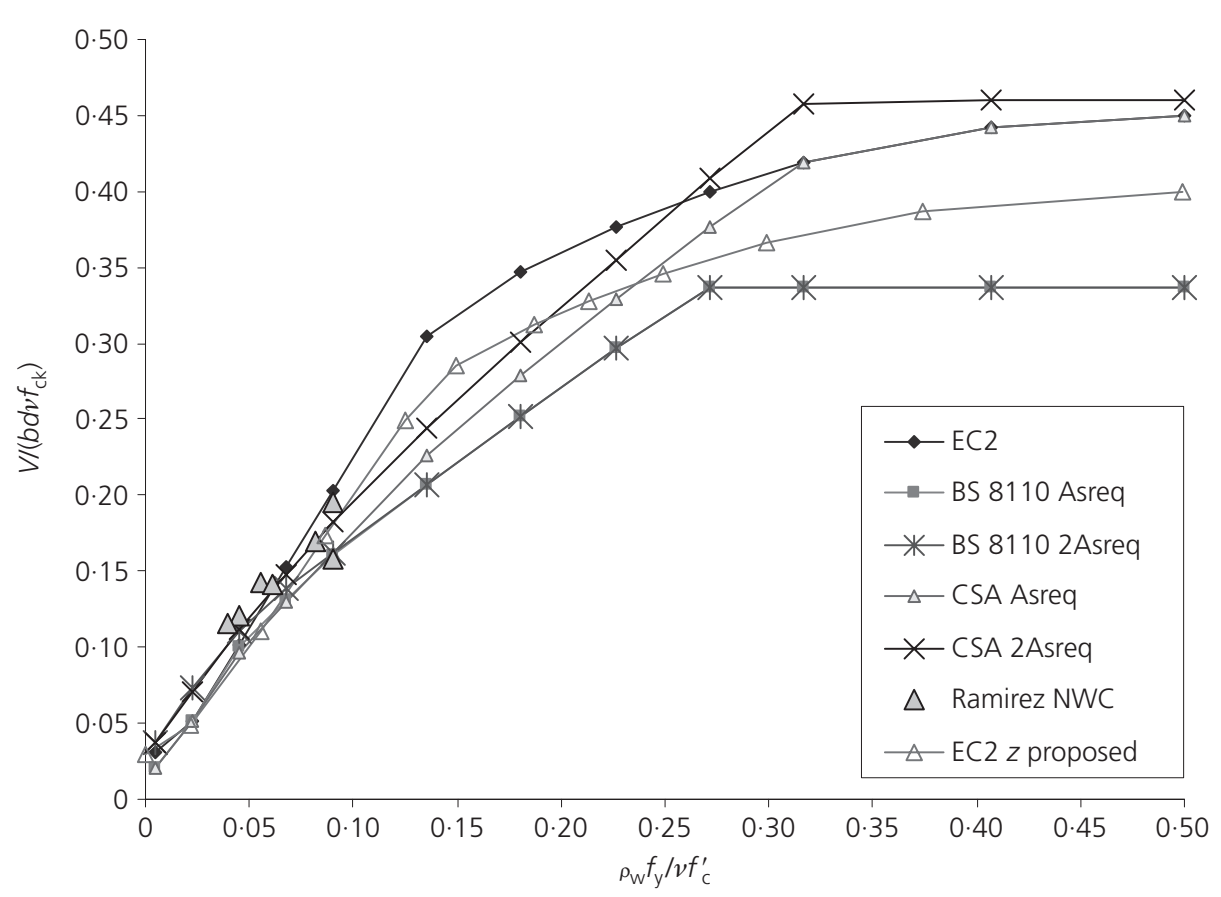

(a)

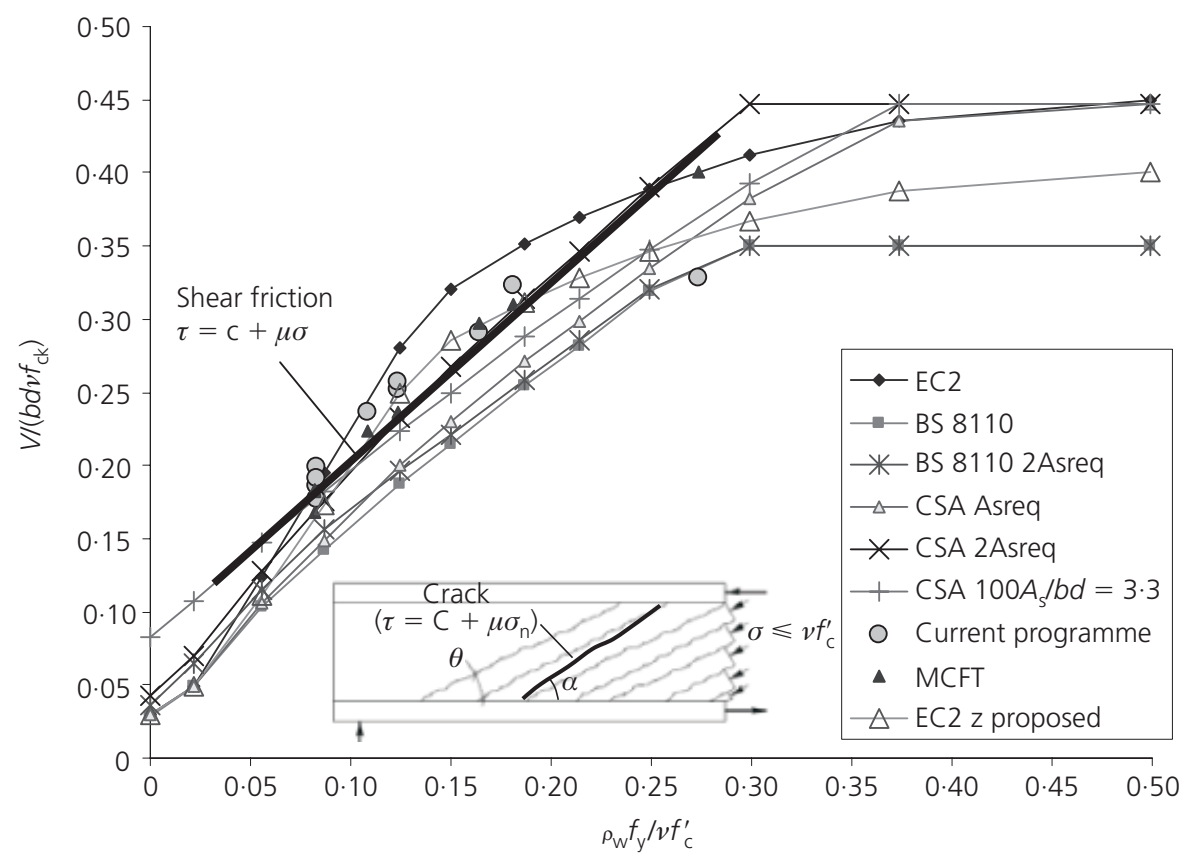

(b)

Figure 11. Influence of stirrup index $\left(\mathrm{SI}=\rho_{\mathrm{w}} f_{\mathrm{y}} / v f_{\mathrm{c}}^{\prime}\right)$ on shear strength predicted by EC2, CSA and BS 8110 for beams with geometry used in tests of (a) Ramirez et al. (2004); and (b) this programme

\section{Conclusions}

The experimental results presented in this paper show that the shear strength of beams without shear reinforcement is reduced by aggregate fracture. Similar findings have been reported by
Regan et al. (2005) among others. The UK national annex to EC2 (BSI, 2004) accounts for aggregate fracture by limiting the concrete cylinder strength to $50 \mathrm{MPa}$ in the design equations for shear. This restriction was found to be necessary but only just 


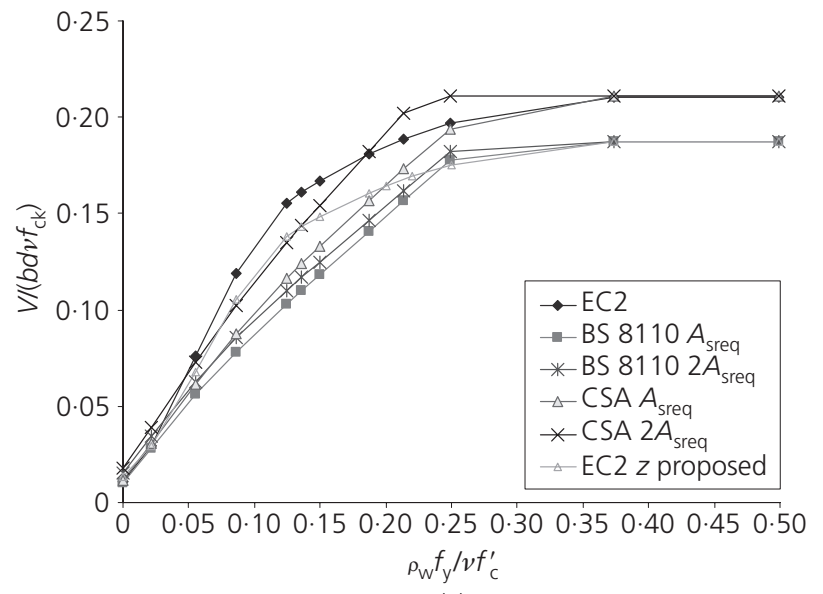

(a)

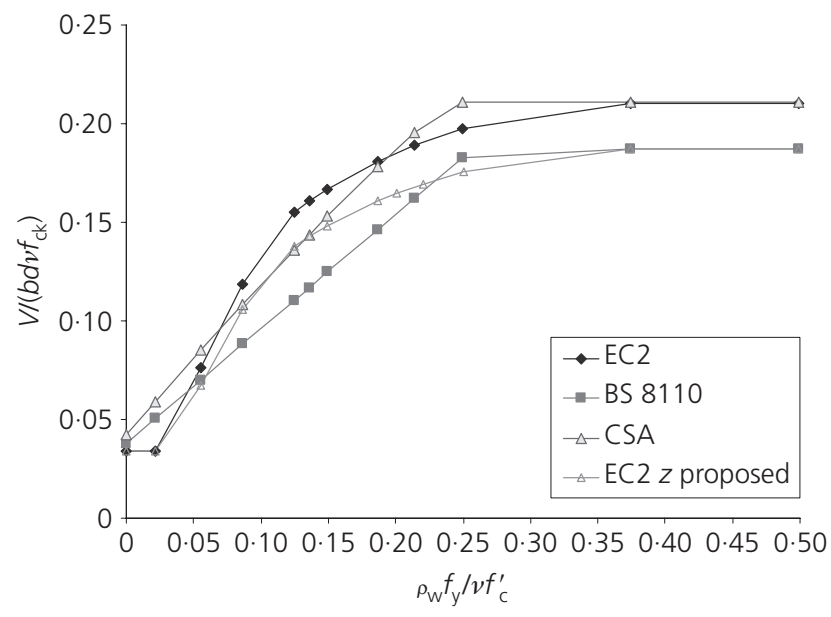

(b)

Figure 12. Influence of stirrup index $\left(S I=\rho_{\mathrm{w}} f_{\mathrm{y}} / v f_{\mathrm{c}}^{\prime}\right)$ on the characteristic design shear strength for EC2, CSA and BS 8110 with: (a) $A_{\text {sprov }}=A_{\text {sreq }}$ and $A_{\text {sprov }}=2 A_{\text {sreq }}$; and (b) $100 A_{s} / b d=3 \cdot 3 \%$.

sufficient for the safe prediction of the design shear strength of the authors' beams without stirrups. The authors found no evidence that the shear strength of their beams with stirrups was reduced by aggregate fracture.

The authors tested ten rectangular beams with stirrups of which eight were continuous. The shear strengths of the tested beams are shown to be consistent with the strengths of similar beams tested in Japan but significantly less than the strengths of the 'I' and ' $\mathrm{T}$ ' section beams used to validate the EC2 design method for shear (Walraven, 2004). The increased strength of the 'I' and ' $T$ ' sections (10-20\%) results from the contribution of the compression flange which was not subtracted from the overall shear capacity in the validation of EC2 (Walraven, 2004). This is significant since EC2 assumes, like BS 8110 and CSA A.23.3-04, that shear is entirely carried by the web. EC2 tends to overestimate the shear strength of the rectangular beams tested in this project if the lever arm for shear is taken as $0.9 d$ as recommended in the code.

Sixty-two continuous beams with rectangular cross-sections were analysed to compare the factors of safety (FOS) for shear failure implicit in EC2, BS 8110 and CSA A.23.3-04. The analysis showed (see Table 5(b)) that EC2 can have a lower FOS for shear in rectangular sections than flexure when $\mathrm{SI}=\rho_{\mathrm{w}} f_{\mathrm{y}} / v f_{\mathrm{c}}^{\prime}>0.05$ which seems undesirable. The authors believe that the FOS for shear should be greater than for flexure (when the areas of flexural and shear reinforcement equal that required for strength) as shear failure occurs suddenly with little if any warning. Therefore, the authors propose that the FOS for shear should be increased in sections without compression flanges by reducing the lever arm for shear from $z=0 \cdot 9 d$ to $z=0 \cdot 8 d$ for sections with $\rho_{\mathrm{w}} f_{\mathrm{y}} / v f_{\mathrm{c}}^{\prime} \geqslant 0 \cdot 05$. This amendment makes the FOS for shear in EC2 more comparable to that in CSA A.23.3-04.

\section{Acknowledgements}

The authors would like to acknowledge the financial support of the Fundación Caja Madrid and thank the staff of the Concrete Structures Laboratory at Imperial College London.

\section{REFERENCES}

Angelakos D, Bentz EC and Collins MP (2001) Effect on concrete strength and minimum stirrups on shear strength of large members. ACI Structural Journal 98(3): 290-300.

Bentz EC (2000) Section Analysis of Reinforced Concrete Members. PhD thesis, University of Toronto.

BSI (British Standards Institution) (2004) European Standard EN-1992-1-1:2004. Eurocode 2: Design of concrete structures. Part 1: General rules and rules for buildings. BSI, London.

BSI (2005) UK national annex to Eurocode 2: design of concrete structures. Part 1: General rules and rules for buildings. BSI, London.

BSI (2007) BS 8110, Part 1:1997: Structural use of concrete: code of practice for design and construction. BSI, London.

Collins MP, Bentz EC, Sherwood EG and Xie L (2008) An adequate theory for the shear strength of reinforced concrete structures. Magazine of Concrete Research 60(9): 635-650.

Concrete Society (1998) Design Guidance for High Strength Concrete. Concrete Society, Camberley, Technical report 49.

CSA (Canadian Standards Association) (2004) CSA A.23.3-04: Design of concrete structures. CSA, Ontario.

Hamadi YD and Regan PE (1980) Behaviour of normal and lightweight aggregate beams with shear cracks. The Structural Engineer 58B(4): 71-79.

Lachemi M, Hossain KMA and Lambros V (2005) Shear resistance of self-consolidating concrete beams - experimental investigations. Canadian Journal of Civil Engineering 32(6): 1103-1113.

Leonhardt F and Walther R (1961) The Stuttgart Shear Tests 1961. A translation of the articles that appeared in Beton und Stahlbetonbau, 1961, 56, No. 12, and 1962, 57, No. 2, 3, 6, 7 
and 8. Cement and Concrete Association Library Translation No. 111, Wexham Springs, UK, December 1964.

Levi F and Marro P (1993) Shear tests on HSC prestressed beams - proposals of new interpretative models. Proceedings of a Conference on High Strength Concrete, Lillehammer, pp. 293-305.

Moayer H and Regan PE (1974) Shear strength of prestressed and reinforced concrete T-beams. ACI Special Publication 42(1): $183-221$.

Muhidin NA and Regan PE (1977) Chopped steel fibres as shear reinforcement in concrete beams. Proceedings of Conference on Fibre Reinforced Materials - Design and Engineering Applications, ICE, London, pp. 135-149.

Muttoni A and Fernández Ruiz M (2008) Shear strength of members without transverse reinforcement as function of critical shear crack width. ACI Structural Journal 105(2): $163-172$.

Muttoni A, Schwartz J and Thürlimann B (1989) Design and Detailing of Reinforced Concrete Structures Using Stress Fields. Swiss Federal Institute of Technology, Zürich.

Nielsen MP and Baestrup MW (1976) Plastic Shear Strength of Reinforced Concrete Beams. Technical University of Denmark, Lyngby.

Pansuk W and Sato Y (2007) Shear mechanism of reinforced concrete T-beams with stirrups. Journal of Advanced Concrete Technology 5(3): 395-408.

Placas A (1969) Shear Strength of Reinforced Concrete Beams. PhD thesis, Imperial College of Science and Technology. London.

Ramirez JA, Olek J and Malone BJ (2004) Shear Strength of Lightweight Reinforced Concrete Beams. American Concrete Institute, Farmington Hills, Michigan, ACI-Special Publication SP218-5, 202 pp.

Regan PE (1971) Shear in Reinforced Concrete - An Experimental Study. Construction Industry Research and Information Association (CIRIA), London, report.

Regan PE and Reza-Jorabi H (1987) The shear resistance of reinforced concrete I-beams. Studi e Ricorche, Politecnico de Milano 19: 305-321.

Regan PE, Kennedy-Reid IL, Pullen AD and Smith DA (2005)
The influence of aggregate type on the shear resistance of reinforced concrete. The Structural Engineer 8(23/24): 27-32.

Sagaseta J (2008) The Influence of Aggregate Fracture on the Shear Strength of Reinforced Concrete Beams. PhD thesis, Imperial College London, London.

Sagaseta J and Vollum RL (2011) Influence of aggregate fracture on shear transfer through cracks in reinforced concrete. Magazine of Concrete Research, in press.

SIA (Swiss Society of Engineers and Architects) (2003) SIA Code 262 for Concrete Structures. SIA, Zurich.

Sörensen HC (1974) Shear Tests on 12 Reinforced Concrete T-beams. Structural Research Laboratory, Technical University of Denmark, Lyngby, Report R60.

Taylor HPJ (1970) Investigation of the Forces Carried Across Cracks in Reinforced Concrete Beams in Shear by Interlock of Aggregate. Cement and Concrete Association, London, technical report 42.447.

Vecchio FJ and Collins MP (1986) The modified compression-field theory for reinforced concrete elements subjected to shear. ACI Journal 83(2): 219-231.

Walraven JC (2004) Shear, background document for prENV 1992-1-1:2001. In Eurocode 2 Background Documents from ENV to EN 1992-1-1 (Whittle R (ed.)). The Concrete Centre, Camberley.

Walraven JC and Al-Zubi N (1995) Shear capacity of lightweight concrete beams with shear reinforcement. Proceedings of Symposium on Lightweight Aggregate Concrete, Sandefjord, Norway, vol. 1, pp. 91-104.

Walraven JC and Stroband J (1994) Shear friction in highstrength concrete. Proceedings of the ACI International Conference on High Performance Concrete, Singapore, SP149, pp. 311-330.

Walraven JC and Stroband J (1999) Shear capacity of high strength concrete beams with shear reinforcement. Proceedings of a Symposium on High Strength Concrete, Sandefjord, Norway, vol. 1, pp. 693-700.

Watanabe $\mathrm{F}$ and Lee JY (1998) Theoretical prediction of shear strength and failure mode of reinforced concrete beams. ACI Structural Journal 95(6): 749-757.

\section{WHAT DO YOU THINK?}

To discuss this paper, please submit up to 500 words to the editor at www.editorialmanager.com/macr by 1 August 2011. Your contribution will be forwarded to the author(s) for a reply and, if considered appropriate by the editorial panel, will be published as a discussion in a future issue of the journal. 